Ann. Biol. anim. Bioch. Biophys., 1978, 18 (6), 1247-1271.

\title{
Relations physiologiques entre le magnésum et l'os
}

\author{
par A. POINTILLART, L. GUEGUEN
}

Station de Recherches de Nutrition, I.N.R.A., 78350 Jouy-en-Josas, France.

Summary. The physiological relation between magnesium and bone.

The various aspects of the physiological relation between magnesium and bone are reviewed. The skeleton contains about 65 p. 100 of the magnesium in the organism. Bone magnesium is a surface ion of hydroxyapatite and is thus very labile, especially when the diet is deficient in magnesium. Blood magnesium level depends on bone magnesium content, which decreases with age and varies little with bone type or species.

Deficiency or excess of magnesium causes histological and mechanical modifications in the bone. Magnesium is implicated in bone mineral solubility, in alkaline phosphatase activity and in calcium renewal. Excess magnesium enhances resorption and magnesium deficiency inhibits it.

In all species but rat the low plasma $\mathrm{Mg}$ due to magnesium deficiency is usually accompanied by hypocalcemia, inhibition of PTH synthesis, secretion or activity. However, hypomagnesemia alone may stimulate the parathyroid glands. Hypermagnesemia induces calcitonin secretion but CT administration does not always cause hypomagnesemia. By decreasing the effects of PTH or vitamin D on calcium metabolism, $\mathrm{Mg}$ deficiency may increase the calcium content of bone ash. Excess vitamin D or rickets causes hypomagnesemia due to conservation of bone magnesium.

Some of the contradictory data in the literature on the effects of magnesium on bone calcium metabolism are discussed. However, magnesium is implicated in bone physiology, even if its role is different from that of calcium, $i$. e. in the endocrine regulation of blood calcium.

\section{Introduction.}

Le squelette est le principal réservoir de magnésium de l'organisme et déjà les travaux de Kruse, Orent, McCollum (1932) et de Tufts et Greenberg (1938) avaient montré que le magnésium osseux était mobilisable lors de carence en magnésium. Le magnésium a toujours suscité des recherches très nombreuses car il joue à la fois un rôle comme constituant de l'os, mais également comme cofacteur de nombreuses enzymes (phosphatases alcalines par exemple). Toutefois, son rôle et les facteurs de son homéostasie sanguine ne sont pas aussi bien connus que dans le cas du calcium. Le squelette peut perdre presque complètement son magnésium pour compenser l'hypomagnésémie ; ainsi, en carence prolongée du bouvillon, la chute peut aller jusqu'à 75 p. $100 \mathrm{du} \mathrm{Mg}$ osseux (Blaxter ef Sharman, 1955) ce qui n'est jamais le cas pour le calcium.

Des travaux expérimentaux ef des revues de synthèse ont essayé d'améliorer les 
connaissances sur cet élément et notamment ses relations avec le tissu osseux ef la régulation du métabolisme calcique ; citons les rapports de Larvor et Durlach, de Heaton, de Durlach au premier symposium sur le déficit magnésique en pathologie humaine de 1971, les travaux de Clark et al., la thèse de Nielsen (1974) dont nous nous sommes largement inspirés dans la présente revue.

Nous avons essayé d'actualiser le sujel, compte tenu des résultats récents, notamment en ce qui concerne les rapports entre le magnésium et les principales hormones agissant sur l'os (CT, PTH, 1.25 DHCC). Nous n'avons pas traité toutes les interactions qui mettent en jeu d'autres facteurs comme la vitamine B1, la thyroxine, l'adrénaline, efc... et nous mentionnons seulement les interactions fluor-Mg. L'objet de ce rapport n'étant pas de traiter la pathologie osseuse, nous avons voulu circonscrire cette revue aux aspects physiologiques des relations $\mathrm{Mg}-\mathrm{Os}$.

Nous nous sommes limités à l'influence directe du magnésium sur l'os (composition, caractères histologiques et mécaniques) ou à l'influence indirecte sur la physiologie osseuse (renouvellement, régulation hormonale) ainsi qu'à l'influence de quelques hormones sur le magnésium de l'os.

\section{Le magnésium dans l'os}

1. Localisation ef taux moyens.

Le squelette contient environ 65 p. 100 du magnésium de l'organisme (Widdowson ef al., 1951 ; Forbes ef al., 1956). Les taux moyens de $\mathrm{Mg}$, quels que soient l'os et l'espèce

TABLEAU 1

Influence du type d'os ef de l'espèce sur la composition centésimale des os en $\mathrm{Mg}$

\begin{tabular}{|c|c|c|}
\hline Type d'os ou espèce & Mg en p. 100 des cendres & $\begin{array}{l}\mathrm{Mg} \text { en } \mathrm{p} .100 \text { de la matière } \\
\text { sèche dégraissée }\end{array}$ \\
\hline Os en général ..... & $0,61(6)$ & - \\
\hline Fémur $\ldots \ldots \ldots \ldots$ & $0,63(19)$ & $0,40(13)$ \\
\hline Tibia ........... & $0,76(3)$ & $0,38(4)$ \\
\hline Humérus ........ & $0,53(6)$ & $0,48(3)$ \\
\hline Vertèbres ........ & $0,57(4)$ & $0,36(3)$ \\
\hline Métacarpe ....... & - & $0,44(6)$ \\
\hline Radius ........... & - & $0,44(14)$ \\
\hline Clavicule ........ & - & $0,39(1)$ \\
\hline Sternum ......... & - & $0,39(2)$ \\
\hline Dent f émail .... & 一 & $0,26(2)$ \\
\hline Yeril dentine .... & & $0,80(2)$ \\
\hline Squelette entier .... & $0,64(1)$ & $0,35(1)$ \\
\hline Rat $\ldots \ldots \ldots \ldots$ & $0,69(20)$ & $0,40(19)$ \\
\hline Homme ......... & $0,60(2)$ & - \\
\hline Bovin .......... & $0,55(18)$ & $0,38(5)$ \\
\hline Chèvre.......... & - & $0,42(3)$ \\
\hline Mouton ......... & $0,63(3)$ & $0,39(1)$ \\
\hline Poulain ......... & $0,55(1)$ & - \\
\hline Chien $\ldots . .$. & $0,70(1)$ & - \\
\hline Porc ............ & - & $0,46(18)$ \\
\hline
\end{tabular}

(-) entre parenthèses : le nombre des données ufilisées pour le calcul (références marquées d'un * dans la bibliographie) 
animale, sont de 0,6 p. 100 des cendres (calcul sur 38 données bibliographiques) et de 0,4 p. 100 de l'os sec dégraissé (calcul sur 47 données). Le tableau 1 montre qu'il n'existe pas de différences significatives d'une espèce à l'aufre ou d'un os à l'autre, sauf peut-être pour la dentine, plus riche en $\mathrm{Mg}$, ef l'émail, plus pauvre (Armstrong et Brekhus, 1937). Chez le porcelet, nous avons constaté que $\mathrm{Mg}$ diaphysaire $(0,6 \mathrm{p} .100)$ est significativement plus élevé que $\mathrm{Mg}$ épiphysaire (0,4 p. 100).

Le magnésium est un ion de surface de l'hydroxyapatite, qui ne pénètre pas dans les interstices cristallins, mais demeure dans l'enveloppe hydratante (Neuman et Mulryan, 1971). L'hydroxyapatite contient $33 \mathrm{mM}$ de $\mathrm{Ca}$ pour $3 \mathrm{mM}$ de $\mathrm{Mg}$ (Neuman et Neuman, 1958). Le magnésium et les citrates se trouvent dans l'os en quantités équimoléculaires. Le rapport pondéral entre $\mathrm{Mg}$ et $\mathrm{Ca}$ est de l'ordre de 1/50 (Morris et O’Dell, 1961 ; Walser, 1967).

2. Facteurs de variation de la teneur en magnésium de l'os.

\subsection{L'Age.}

La teneur en Mg total de l'os diminue avec l'âge (Alfrey, Miller et Trow, 1974), comme la teneur en magnésium échangeable mesuré avec ${ }^{28} \mathrm{Mg}$ (Breibart ef al., 1960). Cette diminution est due à un changement de la taille du cristal osseux : l'os néoformé a des cristaux plus petits, à surface plus faible et le nombre de cations $\mathrm{Mg}^{++}$de surface est donc diminué (Alfrey, Miller et Trow, 1974). Le magnésium osseux est moins mobilisable chez le rat adulte que chez le jeune. Ainsi, Smith et Nisbet $(1968,1972)$ observent une chute de 50 p. 100 chez le jeune et de 22 p. 100 seulement chez l'adulte soumis à une carence identique. De même, Alfrey, Miller et Trow (1974) observent une diminution de 37 p. 100 après 8 jours de carence chez le rat sevré, alors qu'après 3 semaines chez le rat de plus de 5 mois recevant le même régime, la diminution n'est que de 12 p. 100 .

\subsection{La carence en magnésium.}

Le magnésium de l'os peut servir de réserve en cas de carence, ce qui est connu depuis très longtemps (Kruse, Orent et McCollum, 1932 ; Orent, Kruse et McCollum, 1934 ; Tufts et Greenberg, 1938). Cela a été confirmé dans diverses espèces (tabl. 2 et 3 ) comme le rat (Mclntyre et Davidson, 1958), le cobaye (Morris ef O'Dell, 1961), le chien (Chiemchaisri ef Phillips, 1963), le veau (Blaxter, Rook et McDonald, 1954 ; Larvor ef al., 1964), le lapin (Aikawa ef David, 1969), le porc (Miller ef al., 1965a ef 1965b), le poulain (Harrington, 1975), la poule (Cox et Sell, 1967), ef la souris (Nielsen, 1973).

La chute de $\mathrm{Mg}$ osseux (tabl. 2) est en relation avec le temps de carence (Harrington, 1975 ; Smith et Nisbet, 1968, 1972 ; Alfrey ef al., 1974 ; Martindale et Heaton, 1964 ; Rayssiguier et Larvor, 1978). Bien que cette diminution dépende beaucoup des régimes carencés utilisés par rapport aux régimes témoins, il semble qu'en général, en dessous de 200 ppm de $\mathrm{Mg}$, elle soit toujours significative : de 20 à 70 p. $100 \mathrm{de} \mathrm{Mg}$ total de l'os. Lorsque dans une même expérience on peut comparer les effets d'apports variables de $M g$ (tabl. 2), la chute du taux de Mg osseux est d'autant plus importante que le niveau d'apport est faible. Au cours d'une carence prolongée de 500 jours, Heroux, Peter ef Tanner (1975) observent une chute de 60 p. 100 par rapport aux rats témoins avec un régime modérément carencé $(120 \mathrm{ppm})$. Ce fait et l'analyse des données du tableau 2 indiquent qu'environ 30 à 40 p. 100 du magnésium osseux n'est pas mobili- 
TABLEAU 2

Influence du niveau et de la durée de la carence $\mathrm{Mg}$ sur le contenu en $\mathrm{Mg}$ de l'os chez le rat

\begin{tabular}{|c|c|c|c|c|}
\hline \multicolumn{2}{|c|}{ Régimes (ppm) } & \multirow{2}{*}{ Durée } & \multirow{2}{*}{$\begin{array}{l}\text { Chute du Mg osseux en } \\
\text { p. } 100 \text { des témoins }\end{array}$} & \multirow{2}{*}{ Références } \\
\hline témoin & carencé & & & \\
\hline $\begin{array}{l}500 \\
500\end{array}$ & $\begin{array}{r}50 \\
5\end{array}$ & $\begin{array}{l}10 \text { sem. } \\
10 \text { sem. }\end{array}$ & $\begin{array}{l}55,8 \\
53,5\end{array}$ & $\begin{array}{l}\text { Smith et Nisbet, } 1968 \\
\text { rat jeune }\end{array}$ \\
\hline $\begin{array}{l}500 \\
500\end{array}$ & $\begin{array}{l}5 \\
5\end{array}$ & $\begin{array}{l}3 \text { sem. } \\
11 \text { sem. }\end{array}$ & $\begin{array}{l}16,7 \\
22,0\end{array}$ & $\begin{array}{l}\text { Smith ef Nisbet, } 1972 \\
\text { rat adulte }\end{array}$ \\
\hline non précisé & & $\begin{array}{l}3 \text { jours } \\
6 \text { sem. }\end{array}$ & $\begin{array}{l}14,7 \\
44,2\end{array}$ & $\begin{array}{l}\text { Alfrey, Miller et Trow, } 1974 \\
\text { rat adulte }\end{array}$ \\
\hline 430 & 120 & 7 sem. & 56,1 & $\begin{array}{l}\text { Forbes, } 1964 \\
\text { rat sevré }\end{array}$ \\
\hline $\begin{array}{l}690 \\
690 \\
690 \\
490 \\
490 \\
490\end{array}$ & $\begin{array}{r}95 \\
185 \\
370 \\
80 \\
170 \\
280\end{array}$ & $\begin{array}{l}4 \text { sem. } \\
4 \text { sem. } \\
4 \text { sem. } \\
4 \text { sem. } \\
4 \text { sem. } \\
4 \text { sem. }\end{array}$ & $\begin{array}{l}66,3 \\
28,9 \\
\text { NS } \\
65,4 \\
42,3 \\
\text { NS }\end{array}$ & $\begin{array}{l}\text { Forbes, } 1965 \\
\text { raf sevré }\end{array}$ \\
\hline 180 & 30 & 7 sem. & 63,8 & $\begin{array}{l}\text { Chiemchaisri et Phillips, } 1963 \\
\text { rat sevré }\end{array}$ \\
\hline $\begin{array}{l}400 \\
400\end{array}$ & $\begin{array}{l}3 \\
3\end{array}$ & $\begin{array}{l}15 \text { jours } \\
2 \text { mois }\end{array}$ & $\begin{array}{l}21,3 \\
39,3\end{array}$ & $\begin{array}{l}\text { Martindale et Heaton, } 1964 \\
\text { rat adulte }\end{array}$ \\
\hline $\begin{array}{l}500 \\
500 \\
500 \\
500\end{array}$ & $\begin{array}{r}0 \\
10 \\
50 \\
250\end{array}$ & $\begin{array}{l}7 \text { sem. } \\
7 \text { sem. } \\
7 \text { sem. } \\
7 \text { sem. }\end{array}$ & $\begin{array}{l}19,6 \\
15,7 \\
7,8 \text { NS } \\
3,9 \text { NS }\end{array}$ & $\begin{array}{l}\text { Clark et Belanger, } 1967 \\
\text { rat adulte }\end{array}$ \\
\hline 1500 & 30 & $2 \mathrm{sem}$. & 13,3 & $\begin{array}{l}\text { Larvor ef Rayssiguier, } 1971 \\
\text { rat adulte }\end{array}$ \\
\hline 1500 & 30 & 8 jours & 46,1 & $\begin{array}{l}\text { Rayssiguier, Larvor et Barlet, } \\
1973 \\
\text { rat jeune }\end{array}$ \\
\hline $\begin{array}{l}400 \\
400\end{array}$ & $\begin{array}{r}50 \\
200\end{array}$ & $\begin{array}{l}4 \text { sem. } \\
4 \text { sem. }\end{array}$ & $\begin{array}{r}67,6 \\
8,1\end{array}$ & $\begin{array}{l}\text { Alpan, Oldfield ef Jones, } 1970 \\
\text { rat sevré }\end{array}$ \\
\hline 600 & 60 & 1 mois & 48,6 & $\begin{array}{l}\text { Pointillart, } 1976 \\
\text { rat adulte }\end{array}$ \\
\hline 500 & 120 & 500 jours & 60,0 & $\begin{array}{l}\text { Heroux, Peter et Tanner, } 1975 \\
\text { jeune rat }\end{array}$ \\
\hline $\begin{array}{l}1000 \\
1000 \\
1000\end{array}$ & $\begin{array}{l}40 \\
40 \\
40\end{array}$ & $\begin{array}{l}10 \text { jours } \\
22 \text { jours } \\
30 \text { jours }\end{array}$ & $\begin{array}{l}27,5 \\
50,8 \\
57,9\end{array}$ & $\begin{array}{l}\text { Rayssiguier et Larvor, } 1978 \\
\text { rat jeune }\end{array}$ \\
\hline
\end{tabular}


sable. La mobilisation de $\mathrm{Mg}$ de l'os est très rapide puisque Alfrey, Miller et Trow (1974) constatent que la teneur en $\mathrm{Mg}$ échangeable, étudiée avec ${ }^{28} \mathrm{Mg}$, passe de 20 p. 100 à 6 p. 100 de $\mathrm{Mg}$ osseux total en 6 semaines de carence. Elle peut être aussi très importante puisque Blaxter ef Sharman (1955), sur des veaux hypomagnésémiques, observent jusqu'à 75 p. 100 de perte de $\mathrm{Mg}$ osseux total. La perte de Mg osseux peut être très précoce, puisque après 2 jours de carence, le fémur des rats étudiés par Alfrey et al. (1974) a perdu 15,6 p. 100 en moyenne de son magnésium.

Lors d'une carence en $\mathrm{Mg}$, il peut y avoir substitution des ions $\mathrm{Mg}^{++}$par les ions $\mathrm{Ca}^{++}$(McManus et Heaton, 1970). Ainsi, une tendance à l'augmentation du calcium osseux a pu être observée par certains auteurs dans de telles conditions (Nielsen, 1973 ; Duckworth, Godden et Warnock, 1940 ; Martindale ef Heaton, 1964 ; McAleese et Forbes, 1961 ; Blaxter, 1956 ; Lai, Singer et Armstrong, 1975). Comme nous le verrons plus loin, la carence a des effets sur la secrétion de parathormone et peut également entraîner des variations de la teneur en calcium de l'os. Cela peut expliquer que d'autres auteurs ne trouvent pas de changement du calcium osseux, notamment chez le mouton (Hjerpe, 1968), le cobaye (Morris ef O'Dell, 1961), le poulet (Mehring, 1965) ef le veau (Smith, 1959).

\section{TABLEAU 3}

Influence de la carence en $\mathrm{Mg}$ sur le $\mathrm{Mg}$ osseux dans diverses espèces

\begin{tabular}{|c|c|c|}
\hline Espèces & $\begin{array}{c}\text { Chute du } \mathrm{Mg} \text { osseux } \\
\text { en p. } 100\end{array}$ & Références \\
\hline $\begin{array}{l}\text { Veau de lait } \ldots \ldots \ldots \ldots \ldots \ldots \ldots \\
\text { Veau de lait } \ldots \ldots \ldots \ldots \ldots \ldots \ldots \ldots \ldots \\
\text { Veau de lait } \ldots \ldots \ldots \ldots \ldots \ldots \ldots \\
\text { Veau de lait } \ldots \ldots \ldots \ldots \ldots \ldots \\
\text { Porc }\end{array}$ & $\begin{array}{l}39 \text { à } 57,6 \\
75 \\
14,5 \text { à } 29 \\
47 \text { à } 71\end{array}$ & $\begin{array}{l}\text { Larvor, Girard et Brochart, } 1964 \\
\text { Blaxter et Sharman, } 1955 \\
\text { Parr, } 1957 \\
\text { Smith, } 1959\end{array}$ \\
\hline $\int$ carencé 25 ppm $\ldots \ldots \ldots \ldots$ & $\begin{array}{l}64 \text { ( } 8^{\mathrm{e}} \text { côte) } \\
50 \text { (humérus) }\end{array}$ & Miller ef al., 1965a \\
\hline 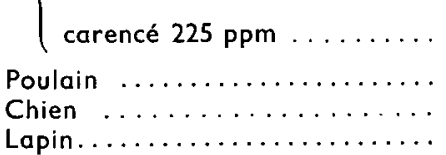 & $\begin{array}{c}42,3 \text { ( } 8^{\mathrm{e}} \text { côte) } \\
21,4 \text { (humérus) } \\
30 \text { à } 44 \\
60 \\
44,4\end{array}$ & $\begin{array}{l}\int \\
\text { Harrington, } 1975 \\
\text { Chiemchaisri et Phillips, } 1963 \\
\text { Aikawa et David, } 1969\end{array}$ \\
\hline
\end{tabular}

Larvor, Girard et Brochart (1964) constatent une augmentation du rapport $\mathrm{Ca} / \mathrm{P}$ dans l'os des veaux carencés, ainsi qu'une diminution de la libération et de l'incorporation du calcium par l'os (mesurées avec ${ }^{45} \mathrm{Ca}$ ) ; Nielsen (1974) pense que cette augmentation est compatible avec la formation de plus d'hydroxyapatite aux dépens du phosphate calcique amorphe.

Une relation entre la teneur en $\mathrm{Mg}$ de l'os et la magnésémie a été observée chez plusieurs espèces comme le veau (Blaxter, 1956), le porc (Miller et al., 1965a et d), le rat (Heaton, 1964).

La carence en magnésium entraîne donc une mobilisation rapide et importante du magnésium osseux, l'effet sur le calcium osseux étant beaucoup plus variable suivant les expériences, avec cependant une tendance à l'augmentation. 


\subsection{La surcharge en magnésium.}

La surcharge en magnésium peut augmenter le contenu en $\mathrm{Mg}$ des os chez le rat (Clark et Belanger, 1967 ; Pointillart, 1976) et chez le porcelet (Pointillart, non publié). Un excès de $\mathrm{Mg}$ peut parfois augmenter la teneur en calcium de l'os et diminuer celle en phosphore (Clark et Belanger, 1967), mais aussi nuire à la fixation du calcium par l'os (Cunningham, 1933). Chez l'homme (Briscoe et Ragan, 1966) et chez le rat (Dowdy et Sauberlich, 1970), l'incorporation du calcium marqué est favorisée par le magnésium.

\section{Disponibilité du magnésium osseux.}

La majeure partie (60 à 80 p. 100) du magnésium osseux est beaucoup plus soluble que le calcium. Dallemagne ef Fabry (1956) et Taylor (1959), par des méthodes diverses d'extraction, arrivent à solubiliser respectivement 60 p. 100 (cendres d'os) et 70 p. 100 (os pulvérisé) du magnésium, les quantités de calcium extraites éłant négligeables. Taylor en conclut qu'il y a deux formes de $\mathrm{Mg}$ dans l'os, l'une relativement soluble et l'autre relativement insoluble dans les acides dilués, et qu'il n'y a pas de quantités significatives de carbonate de $\mathrm{Mg}$ dans l'os, les cations $\mathrm{Mg}^{++}$ou $\mathrm{MgOH}^{+}$ étant adsorbés sur les ions phosphate à la surface des cristaux d'apatite.

L'analyse d'os provenant de différentes parties du squelette de rats sévèrement carencés (Duckworth et Godden, 1941) et de veaux (Blaxter, 1956) indique que le magnésium est perdu uniformément par le squelette entier. Rayssiguier et Larvor (1978) montrent que la déplétion est plus grande dans la métaphyse que dans la diaphyse chez le rat ; ce dernier point est à rapprocher avec le fait que ${ }^{28} \mathrm{Mg}$ est plus rapidement fixé par les épiphyses que les diaphyses (Field, 1961).

\section{Effets généraux de la carence et de la surcharge en magnésium sur les aspects histologiques et mécaniques de l'os}

La carence en magnésium cause des troubles du développement osseux, en particulier une diminution de l'épaisseur du cartilage de croissance chez le rat (Clark et Belanger, 1967 ; Hunt et Belanger, 1972 ; Bogoroch et Belanger, 1975). Smith et Nisbet $(1968,1972)$ constatent une ostéoporose à la fois chez le rat adulte et chez le jeune ef l'attribuent à une réduction de l'activité ostéoblastique. Bussel ef al. (1972) montrent que la carence a des effets sur l'activité des ostéoblastes et des chondroblastes et observent une altération de l'ensemble des cellules osseuses. Deeb, Herrmann et Axt (1974) trouvent en outre une diminution du nombre des lacunes ostéocytaires el des ostéocytes dégénérés. De la fibrose osseuse a été constatée plusieurs fois (Larvor ef al., 1964 ; Belanger et al., 1975) chez le veau et le rat.

Les travaux de Belanger mettent en évidence une prolifération fumorale dans les fémurs des rats carencés (ostéomyélosclérose et tumeurs périostées constituées de fibroblastes et de collagène), ainsi qu'une diminution de l'ostéolyse, de la résorption ostéoclastique ef des effets sur la synthèse des protéines et des mucopolysaccharides (Belanger, 1958). Il peut se produire un épaississement des parois tibiales au niveau de la diaphyse et une augmentation de l'épaisseur du périoste, que Bogoroch ef 
Belanger (1975) attribuent à une diminution de la résorption ; dans la même expérience, ils constatent, par contre, une diminution d'épaisseur du plateau épiphysaire. Ces auteurs concluent à une activité ostéoblastique normale, tandis que la résorption est réduite (alors que l'accrétion est augmentée), ce qui est contradictoire avec les observations d'ostéoporose de Smith et Nisbet. Ni les uns, ni les autres, ne donnent la composition en $\mathrm{Ca}, \mathrm{P}$ et vitamine $\mathrm{D}$ des régimes ; or, on sait depuis les travaux de Randoin et Causeret (1945) que ces facteurs sont déterminants dans le rôle du magnésium sur la croissance osseuse : des rats recevant des régimes pauvres en Ca et/ou en vitamine $D$ présentent des troubles rachitiques moins importants (critères radiographiques) quand l'apport de $\mathrm{Mg}$ est augmenté, ce qui n'est plus le cas avec des régimes bien pourvus en $\mathrm{Ca}$.

La carence en $\mathrm{Mg}$ a des retentissements importants sur l'odontogenèse, le développement dentaire et les constituants de la dent. L'éruption est retardée chez le rat (Weinreb et al., 1973 et Kusner et al., 1973). Chez le cobaye, O'Dell ef al. (1960) observent des exostoses mandibulaires, des incisives érodées, des dents ramollies ef fragiles.

Les examens histologiques et radiographiques de Clark et Belanger (1967) mettent en évidence une immaturité de l'os, tant en surcharge de $\mathrm{Mg}$ (plus de $500 \mathrm{ppm}$ de $\mathrm{Mg}$ pour 0,8 p. $100 \mathrm{Ca}$ et 0,4 p. $100 \mathrm{P}$ ) qu'en carence (moins de 250 ppm). L'excès de $\mathrm{Mg}$ autant que la carence diminue les qualités mécaniques de l'os, notamment la résistance à la rupture, ce qui a été observé chez le rat (Heroux, Peter et Tanner, 1975) ef le mini-porc (Miller ef al., 1965a).

En résumé, il semble donc y avoir convergence des données expérimentales sur la diminution de la résorption (ostéoclasie ef ostéolyse ostéocytaire), en cas de carence Mg. Par contre, les observations sur l'activité ostéoblastique sont discordantes. L'ensemble des travaux indique un ralentissement de la croissance osseuse, par hypoplasie des cartilages de croissance ef une altération des qualités mécaniques de l'os quand le niveau de $\mathrm{Mg}$ alimentaire est inadéquat.

\section{Influence directe du magnésium sur l'os}

\section{Magnésium ef solubilité des sels osseux.}

D'après Neuman et Neuman (1958), le magnésium, in vitro, augmente la solubilité des sels de calcium, notamment de l'hydroxyapatite ; c'est également l'opinion de Pak et Diller (1969). Selon Blumenthal, Betts et Posner (1977) et Nielsen (1973), le magnésium freine la conversion du phosphate calcique amorphe en hydroxyapatite. La résultante de ces deux constatations est donc un effet inhibiteur de $\mathrm{Mg}$ sur la cristallisation minérale osseuse sous forme d'hydroxyapatite. In vitro, Bachra, Trautz et Simon (1965) constatent qu'une concentration de $3 \mathrm{mM}$ de $\mathrm{Mg}$ inhibe la formation des cristaux d'os. Selon Nielsen, Mg exercerait un effet protecteur sur les pyrophosphates en agissant sur les pyrophosphatases ; cependant, cette hypothèse est contredite par d'autres travaux évoqués plus loin.

Les résultats in vivo de Clark ef Belanger (1967) iraient également dans le sens d'une influence défavorable sur la formation d'hydroxyapatite chez des rats ayant reçu une surcharge alimentaire de Mg. En effet, l'augmentation des teneurs de l'os en Ca 
ef $\mathrm{Mg}$ ef la diminution de la teneur en $\mathrm{P}$ n'assuraient pas les meilleures conditions pour la formation de l'hydroxyapatite.

L'action de $\mathrm{Mg}$ sur le collagène osseux n'est pas bien connue mais, dans un travail récent, Rayssiguier, Badinand et Kopp (1978) montrent un ralentissement de l'involution utérine chez la ratte carencée en $\mathrm{Mg}$, due à un ralentissement de la dégradation du collagène par diminution de sa solubilité ; on peut donc imaginer que la carence en $\mathrm{Mg}$ ait un effet similaire au niveau du collagène osseux.

\section{Magnésium ef renouvellement osseux.}

Les travaux in vitro de Pak et Diller (1969) et de McManus et Heaton (1970) montrent qu'il peut y avoir substitution de $\mathrm{Ca}^{++}$par $\mathrm{Mg}^{++}$(et vice versa) par un phénomène physicochimique au niveau de la pellicule liquide adhérant au cristal osseux (enveloppe hydratante), notamment chez le rat âgé (McManus et Heaton). En fait, Mg introduit en excès dans le milieu déplace le calcium dans l'enveloppe sans changer la teneur en phosphates. Cependant, l'accrétion augmente quand la teneur du milieu en $\mathrm{Mg}$ augmente. Inversement, des os provenant de rats carencés en $\mathrm{Mg}$ rejettent moins de calcium et de magnésium dans le milieu d'incubation que les os des rats témoins, sans qu'il y ait un changement significatif pour les phosphates. Toutefois, dans cet essai couplant les effets in vitro et in vivo, il est montré qu'avec l'os métaboliquement actif, $\mathrm{Mg}$ exerce également une action sur la libération d'hydroxyproline, donc une action sur la matrice osseuse. La solubilité du collagène serait-elle modifiée?

Le magnésium en excès favoriserait donc la résorption en agissant sur la libération du calcium de l'os et sur celle d'hydroxyproline. Les observations in vivo de Clark et Geoffroy (1958) chez le rat et de Briscoe et Ragan (1966) en clinique humaine vont également dans ce sens, puisque l'enrichissement du régime en $\mathrm{Mg}$ accélère le renouvellement du calcium marqué. Par contre, Bellavia et Wallach (1973) ne trouvent pas d'effet du magnésium en perfusion in vivo sur le renouvellement osseux de ${ }^{45} \mathrm{Ca}$.

La carence en magnésium chez le veau diminue l'accrétion et la résorption du calcium osseux (Larvor, Girard et Brochart, 1964). Chez le rat, le catabolisme osseux semble être ralenti également, puisque l'hydroxyproline urinaire diminue (McManus ef Heaton, 1969 ; Rayssiguier et Larvor, 1978). Enfin, les essais in vitro (Raisz et Niemann, 1969 ; Nielsen, 1973 ; Cartier et Picard 1955) montrent aussi une chute de la résorption osseuse chez les animaux carencés.

En résumé, l'excès de $\mathrm{Mg}$ accélérerait le renouvellement osseux du calcium, surtout en stimulant la résorption, tandis que le défaut de $\mathrm{Mg}$ ralentirait le renouvellement en diminuant la résorption. L'action sur l'accrétion est mal définie.

\section{Magnésium et phosphatases.}

En carence $\mathrm{Mg}$, il y a diminution de l'activité des phosphatases alcalines du plasma (Smith et Nisbet, 1968, 1972 ; Larvor et al., 1964 ; Larvor ef Durlach, 1971 ; Heaton, 1965a , Pimstone, Einsenberg et Stallone, 1966 ; Hanna ef al., 1960 ; Elin et al., 1971) et du tibia (Loveless et Heaton, 1976), de la pyrophosphatase érythrocytaire (Elin, Armstrong et Singer, 1971) et tibiale des rats (Loveless ef Heaton, 1976). L'addition de Mg augmente l'activité de la phosphatase alcaline chez le rat carencé (Heaton, 1965a; Pimstone, Einsenberg et Stallone, 1966 ; Loveless et Heaton, 1976) ef également de la 
pyrophosphatase inorganique de l'os, chez le rat (Loveless et Heaton) et le poulet (Spierto, Rogler ef Parker, 1969b). Cet effet serait dû, selon Loveless et Heaton, à une action sur la synthèse de ces enzymes. Plusieurs travaux (Wöltgens, Bouting, Bijvoet 1970 ; Sussman et Laga, 1968 ; Melani et Farnararo, 1969) tendent à montrer que pyrophosphatase et phosphatase alcaline sont présentes sur la même enzyme. Dans ces conditions, en carence $\mathrm{Mg}$, la diminution d'activité de ces deux enzymes conduirait à une calcification moindre, c'est-à-dire à une accrétion du calcium diminuée ; inversement, l'apport supplémentaire de magnésium stimulerait l'accrétion, ce qui est observé in vitro dans les expériences de Pak et Diller (1969).

\section{Conclusions.}

Dans l'étude de l'influence du magnésium sur l'os, la notion de seuil semble importante pour expliquer certaines contradictions apparentes. Ainsi, en culture de cartilage, une concentration supérieure à $3 \mathrm{mM}$ inhibe les phosphatases alcalines I et II (Arsenis, Hackett et Huang, 1976), tandis qu'en dessous de $1 \mathrm{mM}$, les phosphatases sont stimulées sous l'effet de $\mathrm{Mg}$. De même, selon Raisz et Niemann (1969), la concentration en $\mathrm{Mg}$ dans le milieu de culture d'os est sans effet sur la libération de ${ }^{45} \mathrm{Ca}$, mais au-dessus de $0,4 \mathrm{mM}$, la résorption diminue. Enfin, pour Nielsen (1973), $1 \mathrm{mM}$ de $\mathrm{Mg}$ en culture de calvaria augmente la libération du calcium de l'os jeune comparativement à un milieu sans magnésium.

En outre, les ions $\mathrm{Mg}^{++}$interviennent dans la synthèse (Peck, Carpenter et Chuster, 1974) et la dégradation de l'AMP cyclique (Slatopolsky et al., 1976), ce qui peut avoir des conséquences sur l'action de la parathormone au niveau osseux.

Les résultats expérimentaux sonł la résultante de tous ces phénomènes : action directe de $\mathrm{Mg}$ sur l'os, action indirecte par les hormones ou par les enzymes. Il semble cependant bien admis que :

- le magnésium «solubilise 》 les sels de calcium,

- la carence en magnésium ralentit le catabolisme osseux,

- la surcharge $\mathrm{Mg}$ accélère le catabolisme osseux,

- la carence Mg diminue l'activité phosphatasique.

Par contre, les effets sur l'accrétion sont controversés : la carence diminuerait l'accrétion, la surcharge pourrait la stimuler (action phosphatasique) ou l'inhiber (action sur l'hydroxyapatite ou les pyrophosphates).

\section{Influence indirecte du magnésium sur l'os}

\section{Magnésium et parathormone.}

La conclusion de nombreux travaux, sur des espèces variées, semble indiquer que la mobilisation du magnésium osseux est possible sous l'influence d'une sécrétion de PTH stimulée par l'hypomagnésémie (Heaton, 1964, 1965b; Walling, Favus et Kimberg, 1975 ; Gitelman, Kukolj et Welt, 1968a et $b$; Pletka et al., 1971 ; Buckle, 1970 ; Cheek et Teng, 1960 ; Eliel et al., 1969). Dans certains cas, la parathyroïdectomie diminue la magnésémie ou augmente le magnésium osseux (Keil, Evans et Prinz, 1974 ; rat ; Payne et Chamings, 1964 : chèvre ; Garel et Barlet, 1974 : rat ; Eliel et al., 1969 : 
rat ; Rayssiguier, 1977 : rat ; David et Anast, 1974 : homme ; Heaton, 1964 : rat), mais tous les résultats ne concordent pas sur ce point : parfois la parathyroïdectomie est sans effet sur la magnésémie ou le magnésium osseux (Larvor et Durlach, 1971).

L'administration de PTH exogène a tendance à élever la magnésémie, bien que ce phénomène ne soit pas constant et que la réponse à la PTH soit très variable dans ses modalités (Larvor ef Durlach, 1971).

Les travaux de Clark et al. (1961-1974) indiquent que le magnésium a des effets sur le métabolisme phosphocalcique qui peuvent apparaître indépendamment de la présence des parathyroïdes chez le rat. Cette équipe a également montré que les effets de la surcharge ou de la carence en $\mathrm{Mg}$ dépendent beaucoup des apports alimentaires en phosphore et en calcium, comme l'ont également montré les travaux de Forbes $(1963,1964,1965)$.

Chez le rat, la carence $\mathrm{Mg}$ provoque une hypercalcémie attribuée à un hyperparathyroïdisme secondaire (Heaton, 1965b; Gitelman, Kukolj et Welt, 1968a ; Durlach, 1969), dont le site d'action serait essentiellement l'absorption calcique (Heaton, 1965b ; McManus ef Heaton, 1969 ; Walling, Favus et Kimberg, 1975).

Chez les autres espèces, la carence $\mathrm{Mg}$ s'accompagne d'une hypocalcémie souvent magnéso-curable. De nombreux auteurs ont attribué cette observation à un hypoparathyroïdisme secondaire (Anast ef al., 1976 ; Estep et al., 1969 ; Eliel ef al., 1969 ; McManus, Heaton et Lucas, 1971 ; Rude et al., 1977 ; Slatopolsky et al., 1977 ; David et Anast, 1974 ; Suh et al., 1973 ; Connor ef al., 1972 ; Chase et Slatopolsky, 1974 ; Levi et al., 1974). Cet hypoparathyroïdisme peut être le fait d'une action, soit sur la synthèse de PTH qui serait inhibée en carence Mg (Suh et al., 1973) surtout à long terme, soit sur la sécrétion de PTH (Levi ef al., 1974 ; Chase et Slatopolsky, 1974 ; Rude et al., 1977 ; Anast et al., 1976), soit encore sur l'efficacité de la PTH au niveau des organes cibles, ce qui a été vu sur le rein (Estep et al., 1969 ; Levi et al., 1974) et sur l'os (Levi ef al., 1974 ; McManus, Heaton et Lucas, 1971 ; Connor ef al., 1972 ; Slatopolsky et al., 1977 ; Estep et al., 1969).

Cependant, ces derniers faits sont parfois controversés. Ainsi, Lee et Roth (1975) et Hamilton ef al. (1971) ne trouvent pas d'effet in vitro de la teneur en $\mathrm{Mg}$ du milieu sur la synthèse nucléique ou sur le contenu en PTH des glandes parathyroides ou sur la réponse à la PTH du tibia d'embryon de poulet (Ramp, Thomas et Nifong, 1977). Enfin Rayssiguier et al. (1977) ne trouvent pas de changement de la teneur en PTH ou en CT du plasma (mesures radioimmunologiques) sur des veaux hypomagnésémiques. Les os des rats carencés en $\mathrm{Mg}$, en incubation, répondent à la PTH en libérant du calcium ef de l'hydroxyproline (Hahn, Chase et Avioli, 1972 ; Anast et al., 1976). Toutefois, selon McManus, Heaton et Lucas (1971), la réponse est plus faible chez les carencés que chez les témoins. Enfin, plusieurs travaux ne révèlent pas de modification des effets urinaires de la PTH (excrétion d'AMPcou de phosphates) en carence Mg (Diaz-Curiel et al., 1977 ; Hahn, Chase et Avioli, 1972) ou des effets osseux mesurés directement ou par l'intermédiaire de la calcémie (Ashby et Heaton, 1975 ; Hahn, Chase et Avioli, 1972 ; Suh ef al., 1972 ; Rayssiguier et Larvor, 1974 ; Stewart et Fleming, 1971).

De nombreux travaux montrent que les glandes parathyroïdes isolées in sifu ou en incubation sont sensibles à la teneur du plasma ou du milieu en magnésium (Sherwood, Herrman et Bassett, 1970 ; Mayer, 1974 ; Care et al., 1966 ; Massry, Coburn et Kleeman, 1970 ; Targovnik, Rodman ef Sherwood, 1971 ; Habener et 
Potts 1976; Buckle, 1970) : l'hypomagnésémie stimule la sécrétion de PTH, tandis que l'hypermagnésémie l'inhibe. Certains auteurs concluent que $\mathrm{Ca}^{++}$et $\mathrm{Mg}^{++}$sont équivalents dans le blocage de la secrétion de PTH (Targovnik, Rodman et Sherwood, 1971 ; Care et al., 1966) tandis que d'autres constatent une réaction bien supérieure avec $\mathrm{Ca}^{++}$(Mayer, 1974 ; Habener ef Potts, 1976). Rude et al. (1977) mettent en évidence une corrélation négative in vitro ef in vivo entre $\mathrm{Mg}$ plasmatique et la $\mathrm{PTH}$ mesurée par radioimmunologie.

En résumé, les interactions Mg-PTH donnent des résultats contradictoires, puisque la carence peut à la fois stimuler la secrétion de PTH ef inhiber son action sur certains organes cibles, dont l'os. Il n'est pas encore bien établi que l'hypomagnésémie entraîne un hypoparathyroïdisme dont le symptôme le plus courant est l'« hypocalcémie magnésiprive ". En outre, notamment chez le rat, certains auteurs concluent à une tendance à l'hyperparathyroïdisme en carence Mg. Enfin, la surcharge Mg par elle-même provoquerait un hypoparathyroïdisme secondaire.

Les niveaux des seuils de carence et les délais (temps de carence ou laps de temps dans lequel on mesure la PTH) expliquent certaines contradictions; de même, les niveaux d'apport phosphocalcique jouent un rôle très important : un rat carencé en $\mathrm{Mg}$ ne développe pas d'hypercalcémie s'il reçoit un régime pauvre en calcium (McManus et Heaton, 1969).

En conclusion, des interactions importantes existent entre PTH et $\mathrm{Mg}$ et notamment, en cas d'hypomagnésémie et dans certaines conditions, la PTH réagit en libérant le $\mathrm{Mg}$ osseux, bien que le processus ne soit pas aussi évident et aussi sensible que dans le cas de la calcémie. La carence en $\mathrm{Mg}$ aurait plutôt tendance, à plus long terme, à freiner l'action de la PTH, ce qui expliquerait en partie l'hypocalcémie magnésiprive ; des désaccords persistent sur ce plan.

\section{Magnésium et calcitonine.}

Les effets du traitement prolongé par la CT sur le magnésium osseux sont très variables. Ainsi, chez une même espèce, le rat, on trouve à la fois dans une même expérience une augmentation de $\mathrm{Mg}$ osseux dans la clavicule ef une diminution dans les tibias (Sorensen, Hindberg et Bank-Mikkelsen, 1971). Nous-mêmes avons constaté une tendance à la hausse du $\mathrm{Mg}$ dans les vertèbres caudales, le maxillaire et l'humérus de porcelet pour une dose donnée de CT (2,4 u.MRC/kg de poids vif), alors que nous ne trouvons pas d'influence pour une dose inférieure $(0,8 \mathrm{u})$ ou supérieure $(4,8 \mathrm{u})$ pendant trois semaines de traitement. Les effets de la thyroïdectomie sur le magnésium osseux sont également aléatoires. Sur des métacarpiens et des métatarsiens de chèvres dans divers états physiologiques, la thyroïdectomie est sans effet sur le $\mathrm{Mg}$ osseux (Barlet, 1974 ; Barlet ef Garel, 1974).

Cependant, il semble prouvé que le magnésium par voie entérale ou parentérale puisse stimuler directement la secrétion de CT, chez le rat (Nielsen, 1970) ; Radde, Wittermann et Pensuwan, 1968), le porc (Care, Bell et Bates, 1971 ; Pointillart, Garel ef Guéguen, $1978 \mathrm{~b}$; Cooper, 1975 ; Pento et al., 1974 ; Littledike et Arnaud, 1971), la vache (Barlet, 1971), la chèvre (Barlet, Rayssiguier et Larvor, 1974). La calcitonine a une action anti-hypermagnésémiante (Barlet, Rayssiguier et Larvor, 1974 ; Pointillart, Guéguen et Garel, 1977 ; Radde et al., 1968 ; Littledike et Arnaud, 1971), mais elle a également une action hypomagnésémiante chez le porcelet (Pointillart, non 
publié), chez le rat (Nielsen, 1971) et chez l'homme (Sorensen et al., 1970). Cette action n'est pas toujours observée (cf. Larvor et Durlach, 1971), puisque la CT reste le plus souvent sans effet sur la magnésémie de l'animal intact.

En carence Mg, l'effet hypocalcémiant de la CT est prolongé (Farnell et Whitehair, 1971), ce qui peut être dû à une inactivation des parathyroïdes qui ne réagissent pas ou peu à l'administration de CT. L'effet hypocalcémiant de la surcharge en magnésium est attribué à la secrétion de CT, puisque cet effet disparaît lorsque l'on thyroĩdectomise les animaux (Radde et al., 1968 : rat ; Nielsen, 1970 : chat ; Barlet, 1971 : vache) ce qui se surajoute au fait que la surcharge en $\mathrm{Mg}$ diminue la secrétion de PTH (cf. chapitre précédent).

Pour conclure, les effets de la CT sur le magnésium osseux sont mal connus ; par contre, il semble admis que le magnésium puisse stimuler la sécrétion de CT, ce qui a inévitablement des répercussions sur l'os se traduisant par exemple par l'hypocalcémie de la surcharge Mg. Toutefois, la CT est beaucoup moins sensible à la magnésémie qu'à la calcémie et l'effet hypomagnésémiant de la CT est inconstant.

\section{Magnésium, Vitamine $D$ ef os.}

L'administration de $1 \alpha$-hydroxycholécalciférol chez des jeunes bovins (Barlet, 1975) et chez la vache laitière (Sansom ef al., 1976) et l'hypervitaminose D chez le chien (Wallach et al., 1966), chez le rat (Richardson et Welt, 1965), chez la vache laitière (Capen et al., 1966 ; Capen, Cole et Hibbs, 1968) et chez l'homme (Lopez de Novales, 1974), provoquent une hypomagnésémie. Parallèlement, le contenu en $\mathrm{Mg}$ de l'os a tendance à augmenter (Miller et al., 1965c; Wallach et al., 1966). Puche et al. (1976) mettent en évidence une corrélation positive entre le niveau d'ingestion de Solanum glaucophyllum ef le $\mathrm{Mg}$ osseux.

Un certain nombre de travaux tendraient à prouver que la vitamine $D$ intervient dans la mobilisation osseuse du magnésium. Des rats néphrectomisés ont un $\mathrm{Mg}$ osseux augmenté (Letteri et al., 1977) et des patients atteints d'insuffisance rénale chronique présentent une hypomagnésémie qui régresse avec l'administration de vitamine D (Revusova et al., 1977). Chez le porcelet rachitique, le $\mathrm{Mg}$ osseux et plasmatique diminue (Pointillart, Garel et Guéguen, 1978a) ce qui peut être dû à la malabsorption de $\mathrm{Mg}$ (Miller et al., 1965c).

Le métabolisme de la vitamine $D$ serait normal en carence magnésique, mais, d'après des travaux faits chez le rat (Rayssiguier et al., 1974, 1975 ; Lifshitz, Harrison et Harrison $1967 a, b$ ), l'os perdrait de sa sensibilité aux métabolites. Il existe chez l'homme un rachitisme magnéso-curable qui résiste à la vitamine $D$ (Reddy et Sivakumar, 1974).

Le fait que certains auteurs émettent l'hypothèse d'une vicariance possible entre $\mathrm{Mg}$ et vitamine $\mathrm{D}$, va un peu dans le même sens : les conséquences de la carence en $\mathrm{Mg}$ sur le métabolisme phosphocalcique et la croissance de l'os sont d'autant plus graves que le régime est pauvre en $\mathrm{Mg}$ (Smith, 1957, 1961 ; Randoin et Causeret, 1945) ; inversement, la supplémentation du régime en $\mathrm{Mg}$ a un effet bénéfique chez les rachitiques.

Dans les premières heures de l'administration de la vitamine D ou d'un analogue, on peut constater parfois une tendance à la hausse de $\mathrm{Mg}$ plasmatique (Walling et Kimberg, 1975 ; Barlet, 1975, 1976), ce qui peut être d'abord dû à un effet conjugué 
de la vitamine $D$ sur la résorption osseuse ef l'absorption intestinale, effet ensuite annulé au niveau osseux par un hypoparathyroïdisme (Capen ef al., 1966 ; Potts ef al., 1968) ou un hypercalcitoninisme secondaire, comme semble le suggérer l'étude histologique des thyroïdes dans les travaux de Capen et Young (1969).

En conclusion, la surcharge en vitamine $D$ provoquerait une hypomagnésémie, peut être par une action directe ou indirecte de la vitamine D sur l'os, ef la carence en vitamine $\mathrm{D}$ entraîne également une hypomagnésémie. La carence en $\mathrm{Mg}$ diminue la sensibilité de l'os à la vitamine D, ce qui peut expliquer l'aggravation du rachitisme qui en résulte.

\section{Fluor, magnésium et os.}

Plusieurs résultats montrent que l'addition de fluor à des régimes pauvres en magnésium augmente la teneur du squelette en $\mathrm{Mg}$ chez le rat (McCann ef Bullock, 1957), chez l'homme (Zipkin, McClure et Lee, 1960), chez le cobaye (Pyke, Hoekstra ef Phillips, 1967) et chez le chien (Chiemchaisri et Phillips, 1963). Chez le rat carencé en magnésium (Ophaug et Singer, 1976) ef chez le cobaye (O'Dell et al., 1973), il semble que les fluorures aient un effet protecteur sur Mg osseux. Aussi, l'addition de fluorures au régime accentue encore la diminution de l'accrétion déjà constatée chez les rats carencés en Mg par rapport aux rats témoins (Ophaug et Singer, 1976). Selon O'Dell et al. (1973) les fluorures sont sans effet sur la résorption de $\mathrm{Mg}$ osseux chez le cobaye carencé en $\mathrm{MJ}$.

\section{Discussion générale et conclusions.}

\section{La carence en magnésium (fig. 1).}

Le magnésium étant un constituant de l'os, la carence par défaut d'apport aboutit à sa mobilisation d'autant plus facile que $\mathrm{Mg}$ est en position de surface sur le cristal osseux et est donc beaucoup plus labile que le calcium. Certains auteurs pensent que cette mobilisation résulte d'une réaction parathyroïdienne à l'hypomagnésémie. Ce phénomène n'est pas généralement admis, même s'il semble que le taux plasmatique de PTH puisse varier en raison inverse de la magnésémie, au moins dans certaines conditions.

L'argument en faveur d'une réaction parathyroïdienne à la carence en Mg est surtout relié à l'apparition d'une hypercalcémie chez les rongeurs, pour lesquels les travaux sur la carence sont les plus nombreux. Or, il a été établi que cette hypercalcémie magnésiprive du rat disparaissait quand les apports calciques étaient très diminués. Il semble donc que, dans ce cas, l'hypercalcémie provienne d'une très bonne absorption intestinale du calcium. De plus, le taux de PTH circulant n'ayant pas été mesuré chez cette espèce, il n'est pas possible de parler d'hyperparathyroïdisme. Chez le rat, comme chez les autres espèces, on constate généralement une diminution de la résorption osseuse lors de carence en $\mathrm{Mg}$, ce qui peut résulter de plusieurs phénomènes : diminution de l'ostéolyse, diminution à long terme de l'activité de la PTH et du 1.25 D.H.C.C., et peut être diminution de l'activité collagénolytique.

Cette tendance à la diminution de la résorption devrait logiquement se traduire par une augmentation de la teneur en Ca de l'os, ce que certains auteurs seulement ont 
signalé. Cependant, la carence agitégalement en diminuant l'accrétion. Le fait le mieux établi est la chute de l'activité phosphatasique, mais d'autres conséquences de la carence, comme la diminution de l'activité ostéoblastique ef des perturbations de la synthèse des protéines constitutives de la substance ossifiable, pourraient aussi intervenir.

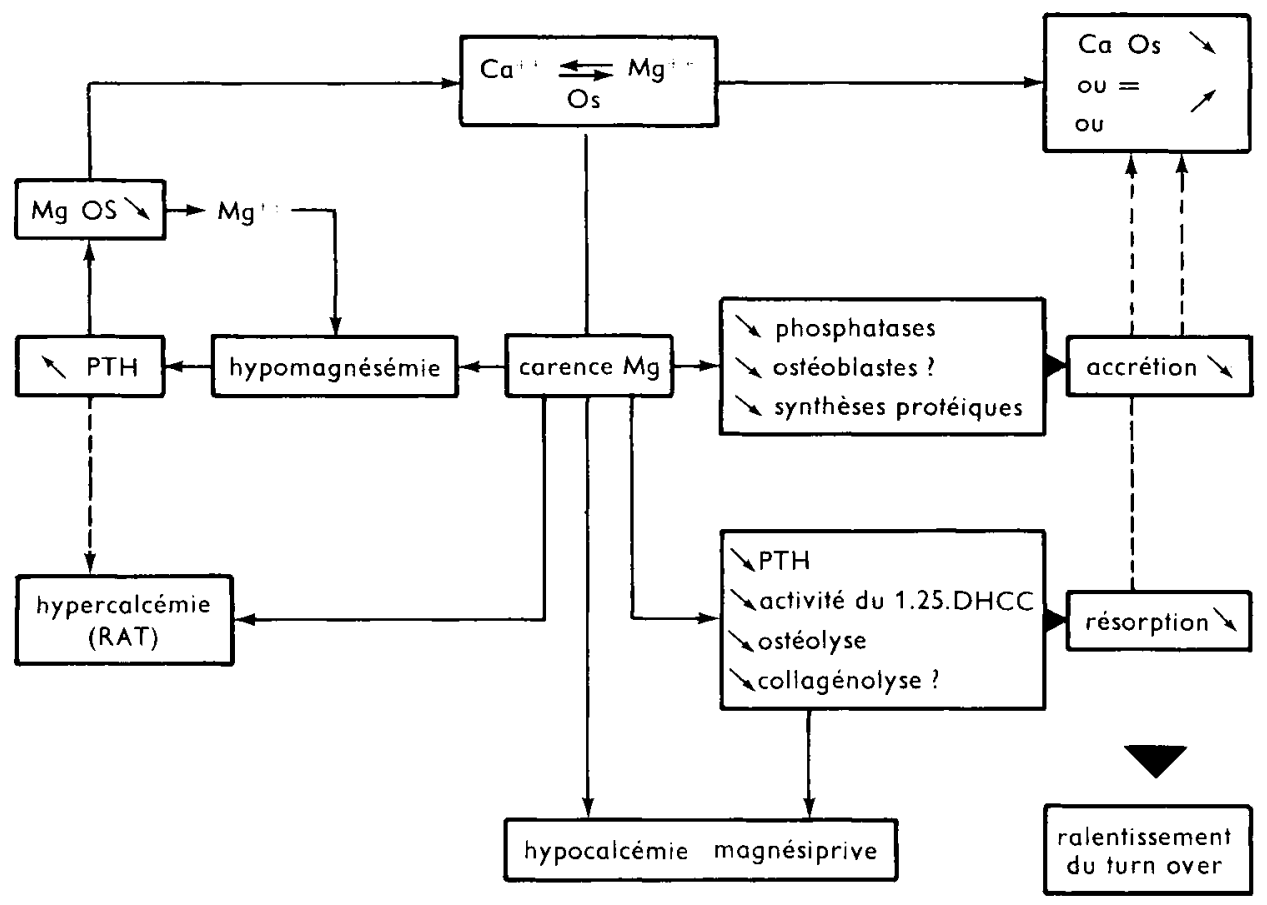

FIG. 1. - Schéma des interactions Mg-Os dans la carence en magnésium.

Le bilan osseux est donc variable d'un essai à l'autre, en fonction de la résultante de la diminution de l'accrétion et de la diminution de la résorption. Le fait que le calcium puisse se substituer au magnésium libéré par l'os joue peu sur le bilan en raison du très faible pourcentage de $\mathrm{Mg}$ contenu dans l'os et de sa superficialité. Cet échange $\mathrm{Ca}^{++} / \mathrm{Mg}^{++}$résulterait d'un processus physico-chimique sans intervention des hormones. Finalement, la carence en $\mathrm{Mg}$ provoque un ralentissement du renouvellement calcique de l'os et une hypocalcémie secondaire qui régresse quand les apports magnésiques sont normalisés.

Le taux de PTH dans le plasma pourrait répondre à la fois à la baisse de la calcémie et à celle de la magnésémie, c'est-à-dire à la somme $\left(\mathrm{Ca}^{++}\right)+\left(\mathrm{Mg}^{++}\right)$. Mais, dans les conditions normales, la réaction parathormonale est surtout sensible aux variations de la calcémie. On admet aujourd'hui que $\mathrm{Mg}$ exerce un effet permissif sur l'action de la PTH au niveau de l'os.

2. La surcharge en magnésium (fig. 2).

Cette surcharge provoque une hypermagnésémie et l'os a tendance à accumuler un excès de $\mathrm{Mg}$. Comme pour la carence, il peut y avoir substitution $\mathrm{Ca}^{++} / \mathrm{Mg}^{++}$, 
en sens inverse cette fois. II ne s'agit pas des ions $\mathrm{Ca}^{++}$de l'hydroxyapatite mais de ceux de l'enveloppe hydratante. Par ailleurs, si l'activité phosphatasique diminue par insuffisance de $\mathrm{Mg}$ (in vivo et in vitro), il n'est pas du tout évident qu'elle augmenterait dans les conditions normales avec un supplément de $\mathrm{Mg}$. Au contraire, au-delà d'un certain seuil, il y aurait inhibition de l'activité phosphatasique. En fait, Mg est essentiel à cette activité enzymatique, mais il n'y a pas de réponse proportionnelle à la concentration de $\mathrm{Mg}$ comme cela peut se produire entre $\mathrm{Mg}$ et la calcitonine. En effet, la surcharge en $\mathrm{Mg}$ provoque une hypocalcémie dont l'origine est l'augmentation du taux de CT ou, plus exactement, cette hypocalcémie ne survient pas chez les animaux dépourvus de cellules $C$ par thyroïdectomie. La surcharge $M g$ aurait également tendance à diminuer la secrétion de PTH, bien qu'il ait été observé une augmentation de la résorption, ce qui est contradictoire. Cette augmentation est attribuée essentiellement à une solubilisation des sels osseux : in vitro, $\mathrm{Mg}$ freine la cristallisation en hydroxyapatite des phosphates calciques amorphes. Il est possible également que la solubilité du collagène ou les collagénases soient stimulées par un excès de $\mathrm{Mg}$, mais aucun travail à ce jour n'a étudié ces phénomènes. En outre, si la sécrétion de CT augmente, il faudrait s'attendre à une résorption diminuée, ce qui n'a pas été observé.

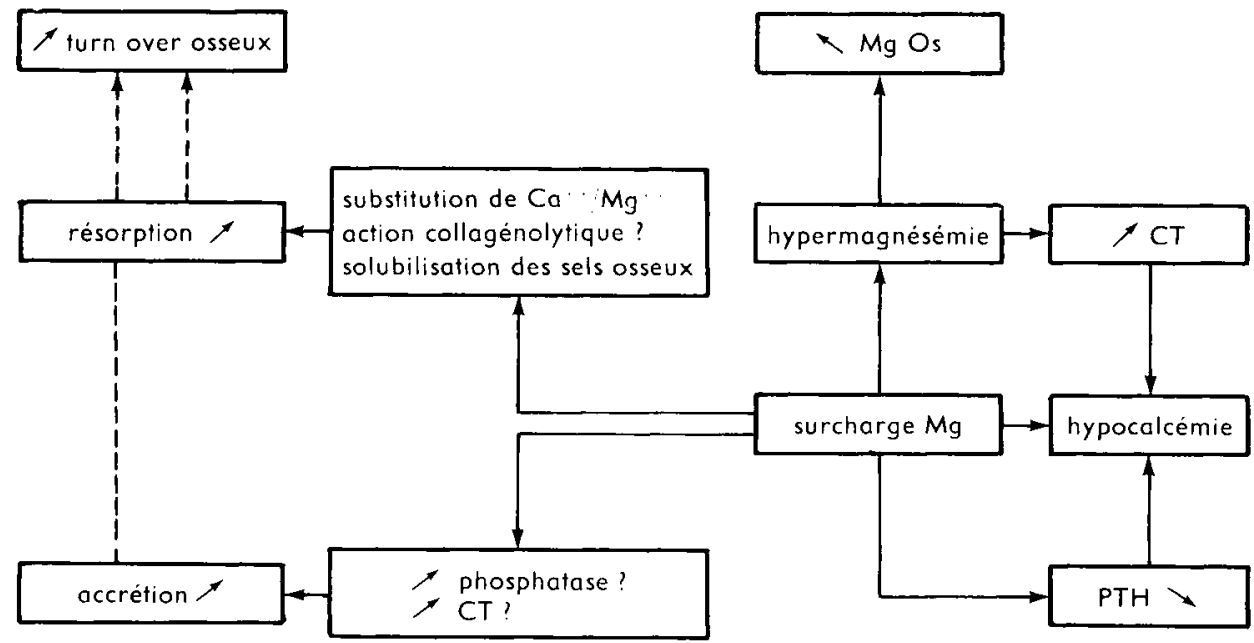

FIG. 2. - Schéma des inferactions Mg-Os dans la surcharge en magnésium.

Comme on peut le voir, les effets de la surcharge sont beaucoup moins évidents que ceux de la carence. Cela tient peut-être aux types d'expérimentation : la carence se réalise par défaut d'apport en $\mathrm{Mg}$, tandis que les travaux sur un excès de $\mathrm{Mg}$ sont souvent le résultat d'expériences in vitro ou de surcharges parentérales (et de courte durée) en $\mathrm{Mg}$, les effets d'une surcharge orale prolongée ayant été rarement étudiés. Dans ce dernier cas, on constate la formation d'un os immature et fibrillaire comme pour la carence : Mg est indispensable à une ossification normale mais apparemment pas au-delà d'un certain niveau. Ce niveau dépend d'autres facteurs alimentaires, notamment des apports de phosphore, de calcium et de vitamine $D$. 
Il nous semblerait intéressant d'éłudier les effets à long terme d'une surcharge en magnésium sur la minéralisation osseuse, non pas que l'alimentation humaine soit trop riche en magnésium, mais parce que les aliments des animaux en sont en général bien pourvus ; en effet, l'utilisation excessive du magnésium peut ne pas être bénéfique : si le magnésium peut, de façon directe, accélérer le furnover du calcium, il peut aussi, de façon indirecte (calcitonine), le ralentir et bien peu de résultats permettent de se faire une idée du bilan. Toutefois, il faut souligner que les effets nocifs de l'excès de $\mathrm{Mg}$ sur l'os, observés dans les expériences de Clark par exemple, se produisent avec des niveaux d'apports 10 fois supérieurs aux recommandations alimentaires, tandis que, dans la pratique, les apports ne sont que 2 ou 3 fois supérieurs aux recommandations. Des travaux sont également nécessaires pour conclure sur l'influence du magnésium sur les pyrophosphatases de l'os : pour certains auteurs, le magnésium protège les pyrophosphates, pour d'autres il active les pyrophosphatases, les deux faits étant contradictoires. II n'existe, à notre connaissance, qu'un seul travail récent (Loveless ef Heaton, 1976) qui montre clairement une baisse de l'activité des pyrophosphatases de l'os en carence $\mathrm{Mg}$, ce qui peut conduire à une chute de l'accrétion, chute renforcée par la diminution de la synthèse des mucopolysaccharides et des protéines et conduisant à un os immature et fibrillaire.

Enfin, un aspect intéressant est le rôle du magnésium dans la synthèse ef la dégradation du collagène : l'hydroxyprolinurie diminue en carence $\mathrm{Mg}$ et, par ailleurs, certains auteurs ont observé de la fibrose osseuse. On peut donc supposer une accumulation anormale de collagène et donc une perturba ion de l'ossification. Cet aspect mérite d'être approfondi comme le suggèrent d'ailleurs Rayssiguier et Larvor dans un travail très récent (1978).

Les tétanies hypomagnésémiques de l'enfant ont beaucoup incité les recherches sur les inferactions Mg-PTH qui demeurent peu claires, l'hypomagnésémie pouvant soit stimuler, soit inhiber la PTH selon les circonstances. Nos résultats actuels sur le porcelet laissent entrevoir des relations étroites, dans cette espèce, entre magnésémie et taux de calcitonine, ce qui n'est pas confirmé dans la tétanie d'herbage de la vache. Les effets de l'administration de PTH, de CT ef de 1.25 DHCC sur le magnésium osseux restent controversés ef il ne semble donc pas y avoir de contrôle en retour entre ces hormones et la magnésémie, comparable à celui de la calcémie. A notre avis, il serait intéressant de mesurer les faux de PTH et de CT dans le plasma pour des régimes carencés ou surchargés en magnésium, les rares données existant chez l'Homme (Rude ef al., 1977) étant insuffisantes pour tirer des conclusions définitives.

Enfin, le magnésium intervenant partout, il n'est pas surprenant de constater son rôle direct ou indirect sur l'os et son métabolisme ; néanmoins, le rôle du magnésium dans l'os n'est pas aussi important que celui du calcium, compte tenu de sa faible concentration $(0,4$ p. 100$)$ et de sa grande labilité.

En conclusion, la carence en magnésium a des effets importants sur le méłabolisme osseux en provoquant une ossification anormale et une diminution des échanges calciques qui seraient le fait surtout d'une diminution de l'activité phosphatasique et d'une réduction de la sensibilité de l'os à la parathormone. Quant à la surcharge, ses conséquences sont moins clairement établies, mais elle peut aboutir également à des perturbations osseuses. On admet généralement qu'elle accélère le renouvellement osseux 
sans que cela soit très bien démontré. La carence s'accompagne presque foujours d'une hypocalcémie, ce qui peut également être le cas de la surcharge ; dans les deux cas, l'hypocalcémie proviendrait de modifications hormonales (PTH ou CT) mais des investigations complémentaires s'avèrent nécessaires pour en déterminer les modalités.

Rapport d'introduction au $5^{\mathrm{e}}$ Colloque français annuel sur le magnésium.

CHU Cochin-Port-Royal, 3 décembre 1977.

Reçu en mars 1978.

Accepté en juillef 1978.

\section{Références}

* AIKAWA J. K., DAVID A. P., 1969. ${ }^{28} \mathrm{Mg}$ studies in magnesium deficient animals. Ann. N. Y. Acad. Sci., 162, 744-757.

* ALfReY A. C., MILLER N. L., TROW R., 1974. Effect of age and magnesium depletion on bone magnesium pools in rats. J. clin. Invest., 54, 1074-1081.

* ALPAN S. O., OLDFIELD J. E., JONES I. R., 1970. Interrelation ships of diefary magnesium, potassium and protein in hypomagnesemia of rats. Ankara Univ. Vet. Fak. Dergisi, 17, 384-393.

ANAST C. S., WINNACKER J. L., FORTE L. R., BURNS T. W., 1976. Impaired release of parathyroid hormone in magnesium deficiency. J. clin. Endocrinol. Metab., 42, 707-717.

* ARMSTRONG W. D., BREKHUS P. J., 1937. Chemical constitution of enamel and dentin. I. Principal components. J. biol. Chem., 120, 677-687.

ARSENIS C., HACKETT M. H., HUANG S. M., 1976. Resolution, specificity and transphosphorylase activity of calcifying cartilage alkaline phosphatases. Calc. Tiss. Res., 20, 159-171.

ASHBY J. P., HEATON F. W., 1975. Effect of magnesium deficiency and parathyroid hormone on cyclic AMP metabolism in rat renal cortex. J. Endocr., 67, 105-112.

BACHRA B. N., TRAUTZ O. R., SIMON S. L., 1965. Precipitation of calcium carbonates and phosphates. III. The effect of magnesium and fluoride ions on the spontaneous precipitation of calcium carbonates and phosphates. Arch. oral. Biol., 10, 731-738.

BARLET J. P., 1971. Role of the thyroid gland in magnesium-induced hypocalcemia in the bovine. Horm. Metab. Res., 3, 63-64.

BARLET J. P., 1974. Rôle physiologique de la calcitonine chez la chèvre gestante ou allaitante. Ann. Biol. anim. Bioch. Bioph., 14, 447-457.

BARLET J. P., 1975. Influence du $1 \alpha$-hydroxycholecalciférol sur la calcémie et la phosphatémie des bovins. C. R. Acad. Sci. Paris, 281, sér. D, 1497-1500.

BARLET J. P., 1976. Prophylaxie ef thérapeutique de l'hypocalcémie vitulaire par les isomères ou les métabolites de la vitamine D. I. Le 5-6 trans 25 hydroxycholécalciférol. Ann. Biol. anim. Bioch. Biophys., 16, 709-718.

* BARLET J. P., GAREL J. M., 1974. Physiological role of calcitonin in pregnant goat and ewes, 119121. In TALMAGe R. V., OWEN M., PARSONS J. A., Proc. 5th Parathyroid Conf., Excerpia med., Int. Congr. Ser. 346.

BARLET J. P., RAYSSIGUIER Y., LARVOR P., 1974. Action anti-hypermagnésémiante de la calcitonine chez le rat et chez la chèvre. C. R. Acad. Sci. Paris, sér. D, 278, 2661-2664.

BELANGER L. F., 1958. Quantitative appreciation by comparative autoradiography of the synthesis and maintenance of some organic constituents of the epiphyseal plate of growing rats in relation with magnesium deficiency. J. Histochem. Cytochem., 6, 146-153.

BELANGER L. F., ROBICHON J., URIST M. R., 1975. The effects of magnesium deficiency on the host response to intramuscular bone matrix implanted in the rat. J. Bone Joint Surg., 57A, 522-526. 
BELLAVIA J. V., WALLACH S., 1973. Effect of phosphate and magnesium infusions in skeletal furnover and renal content of calcium, phosphorus and magnesium in rats. Endocrinology, 93, 1294-1299.

* BLAXTER K. L., 1956. The magnesium content in bone in hypomagnesaemic disorders of livestock, 117-134. In WOLSTENHOLME G. E. W., O'CONNOR C. M., Ciba Found. Symp. on Bone structure and metabolism. Churchill, London.

BLAXTER K. L., ROOK J. A. F., MCDONALD A. M., 1954. Experimental magnesium deficiency in calves I. Clinical and pathological observations. J. comp. Path., 64, 157-175.

BLAXTER K. L., SHARMAN G. A. M., 1955. Hypomagnesemic tetany in beef cattle. Vet. Rec., 67, 176-186.

BLUMENTHAL N. C., BETTS F., POSNER A. S., 1977. Stabilization of amorphous calcium phosphate by $\mathrm{Mg}$ and ATP. Calc. Tiss. Res., 23, 245-250.

BOGOROCH R., BELANGER L. F., 1975. Skeletal effects of magnesium deficiency in normal, ovariectomized, and Estrogen-treated rats. Anat. Rec., 183, 437-438.

BREIBART S., LEE J. S., McCOORD A., FORBES G. B., 1960. Relation of age to radiomagnesium exchange in bone. Proc. Soc. exp. Biol. Med., 105, 361-363.

BRISCOE A. M., RAGAN C., 1966. Effect of magnesium on calcium metabolism in man. Amer. J. clin. Nutr., 19, 295-306.

BUCKLE R. M., 1970. The relation of serum parathyroid hormone to serum calcium and magnesium levels. Proc. roy. Soc. Med., 63, 871-875.

BUSSEL N. E., VOGEL J. J., MEHARG L. S., LEVY B. M., 1972. Magnesium deficiency. I. - The femur in acute magnesium deficiency. Proc. Soc. exp. Biol. Med., 139, 387-389.

CAPEN C. C., COLE C. R., HIBBS J. W., 1968. Influence of vitamin D on calcium metabolism and the parathyroid glands of cattle. Fed. Proc., 27, 142-152.

CAPEN C. C., COLE C. R., HIBBS J. W., WAGNER A. R., 1966. Bioassay and quantitative morphologic analysis of the parathyroid glands, and serum and urine changes in cows fed high levels of vitamin D. Amer. J. vet. Res., 27, 1117-1186.

CAPEN C. C., YOUNG D. M., 1969. Fine structural alterations in thyroid parafollicular cells of cows in response to experimental hypercalcemia induced by vitamin. D. Amer. J. Pathol., 57, 365-382.

CARE A. D., BELL N. H., BATES R. F. L., 1971. The effects of hypermagnesemia on calcitonin secretion in vivo. J. Endocr., 51, 381-386.

CARE A. D., SHERWOOD L. M., POTTS J. T., AURBACH G. D., 1966. Evaluation by radioimmunoassay of factors controlling the secretion of parathyroid hormone. Perfusion of isolated parathyroid gland of the goat and sheep. Nature, 209, 55-57.

CARTIER P., PICARD J., 1955. La minéralisation du cartilage ossifiable. II. - Le système ATPasique du cartilage. Bull. Soc. chim. Biol., 37, 661-675.

CHASE L. R., SLATOPOLSKY E., 1974. Secretion and metabolic efficacy of parathyroid hormone in patients with severe hypomegnesemia. J. clin. Endocrinol. Metab., 38, 363-371.

CHEEK D. B., TENG H. C., 1960 . Changes in tissue composition of the rat in parathyroid intoxication and the effect of magnesium loading. Clin. Sci., 19, 195-208.

* CHIEMCHAISRI Y., PHILLIPS P. H., 1963. Effect of dietary fluoride upon the magnesium calcinosis syndrome. J. Nutr., 81, 307-311.

CLARK I., 1961. Agents effecting the removal of skeletal radiocalcium and radiophosphorus from intact and parathyroidectomized rats, 183-196. In GREEP R. O., TALMAGE R. V., The parathyroids. C. C. Thomas Publ., Springfield, Illinois.

CLARK I., 1969. Effects of magnesium on calcium and phosphate metabolism in parathyroidectomized rats. Endocrinology, 85, 1101-1113.

CLARK I., 1969. Importance of dietary Ca : PO4 ratios on skeletal, $\mathrm{Ca}, \mathrm{Mg}$ and PO4 metabolism, Am. J. Physiol., 217, 865-870.

CLARK I., 1969. Metabolic interrelations of calcium, magnesium and phosphate. Am. J. Physiol., 217, 871-878.

* CLARK I., BELANGER L., 1967. The effects of alterations in dietary magnesium on calcium, phosphate and skeletal metabolism. Calc. Tiss. Res., 1, 204-218.

CLARK I., GEOFFROY R., 1958. Studies in calcium metabolism, J. biol. Chem., 233, 203-205. 
CLARK I., RIVERA-CORDERO F., 1971. Effect of parathyroid function on absorption and excretion of calcium, magnesium and phosphate by rats. Endocrinology, 88, 302-308.

CLARK I., RIVERA-CORDERO F., 1973. Effect of endogenous parathyroid hormone on calcium, magnesium and phosphate metabolism in rats. Endocrinology, 92, 62-71.

CLARK I., RIVERA-CORDERO F., 1974. Effect of endogenous parathyroid hormone on calcium, magnesium and phosphate metabolism in rat. II. Alterations in dietary phosphate. Endocrinology, 96, 360-369.

COOPER C. W., 1975. Ability of several cations to promote secretion of thyrocalcitonin in the pig. Proc. Soc. exp. Biol. Med., 148, 449-454.

CONNOR T. B., TOSKES P., MAHAFFEY J., MARTIN L. G., WILLIAMS J. B., WALSER M., 1972. Parathyroid function during chronic magnesium deficiency. Hopkins Med. J., 131, 100-117.

COX A. C., SELL J. L., 1967. Magnesium deficiency in the laying hen. Poult. Sci., 46, 675-679.

CUNNINGHAM T. J., 1933. The influence of the level of dietary magnesium on the magnesium and calcium contents of the bone, the bodies and the blood serum of rats. N. Z. J. Sci. Tech., 15, 191-198.

DALLEMAGNE M. J., FABRY C., 1956. Structure of bone salts, 14-35. In WOLSTENHOLME G. E. W., O'CONNOR C. M., Ciba Found. Symp. on Bone structure and metabolism. Churchill, London.

DAVID L., ANAST C. S., 1974. Calcium metabolism in newborn infants. The interrelationship of parathyroid function and calcium, magnesium and phosphorus metabolism in normal, " sick " and hypocalcemic newborns. J. clin. Invest., 54, 287-296.

DEEB S., HERRMANN H. J., AXT J., 1974. Zur Pathomorphologie der Skelettstoff-Wechsekstörungen beim experimentellen Magnesiummangel der Ratte. Arch. exper. Vet. Med., 28, 819-845.

DIAZ-CURIEL M., RUIZ-PALOMO F., CASTRILLO J. M., RAPADO A., 1977. The effect of PTE infusion in hypomagnesemic states (Abstr.). 3rd int. Workshop on phosphate and other minerals. Madrid, July 13-15, 1977.

DOWDY R., SAUBERLICH H., 1970. Effect of magnesium upon absorption and distribution of ${ }^{45} \mathrm{Ca}$, Fed. Proc., 29, 565 (Abstr.).

DUCKWORTH J., GODDEN W., 1941. The lability of skeletal magnesium reserves. The influence of rates of bone growth. Biochem. J., 35, 816-823.

DUCKWORTH J., GODDEN W., WARNOCK G. M., 1940. The effect of acute magnesium deficiency on bone formation in rats. Biochem. J., 34, 97-108.

DURLACH J., 1969. Spasmophilie ef déficit magnésique. 141 pp. Masson et Cie, Paris.

DURLACH J., 1971. Déficit magnésique et pathologie ostéoarticulaire, 175-192. In DURLACH J., 1er Symp. int. Déficit magnésique en pathologie humaine, Vittel, 9-15 mai 1971.

ELIEL L. P., SMITH W. O., CHANES R., HAWRYLKO J., 1969. Magnesium metabolism in hyperparathyroidism and osteolytic disease. Ann. N. Y. Acad. Sci., 162, 810-830.

ELIN R. J., ARMSTRONG W. D., SINGER L., 1971. Enzyme, adenosine triphosphate and blood celIular changes in Mg deficient and control rats. Proc. Soc. exp. Biol. Med., 137, 635-640.

ESTEP H., SHAW W. A., WATLINGTON C., HOBE R., HOLLAND W., TUCKER St. G., 1969. Hypocalcemia due to hypomagnesemia and reversible parathyroid hormone unresponsiveness. J. clin. Endocr. Metab., 29, 842-848.

FARNELL D. R., WHITEHAIR C. K., 1971. Influence of thyrocalcitonin in rats fed magnesium-deficient and complete rations Am. J. vet. Res., 32, 131-148.

FIELD A. C., 1961. Studies on magnesium in ruminant nutrition. 3. Distribution of ${ }^{28} \mathrm{Mg}$ in the gastrointestinal tract and tissues of sheep. Brit. J. Nutr., 15, 349-359.

* FORBES R. M., 1963. Mineral utilization in the rat. I. Effects of varying dietary ratios of calcium, magnesium and phosphorus. J. Nutr., 80, 321-326.

* FORBES R. M., 1964. Mineral utilization in the rat. Il. Restoration of normal tissue levels of magnesium and calcium following magnesium deficiency. J. Nutr., 83, 44-48.

* FORBES R. M., 1965. Mineral utilization in the rat. V. Effects of dietary thyroxine on mineral balance and tissue mineral composition with special reference to magnesium nutriture. J. Nutr., 86, 193-200.

FORBES R. M., MITCHELL H. H., COOPER A. R., 1956. Further studies on the gross composition and mineral elements of the adult human body. J. biol. Chem., 223, 969-975.

GAREL J. M., BARLET J. P., 1974. The effects of calcitonin and parathormone on plasma magnesium levels before and after birth in the rat. J. Endocr., 61, 1-13. 
GITELMAN H. J., KUKOLJ S., WELT L. G., 1968a. The influence of the parathyroid glands on the hypercalcemia of experimental magnesium depletion in the rat. J. clin. Invest., 46, 118-126.

GITELMAN H. J., KUKOLJ S., WELT L. G., 1968b. Inhibition of parathyroid gland function in hypermagnesemia. Am. J. Physiol., 215, 483-485.

GRIFFITH F. D., PARKER H. E., ROGLER J. C., 1964. Effects of dietary magnesium and fluoride on the magnesium content of tissues from growing chicks. J. Nutr., 83, 15-19.

* GUEGUEN L., MATHIEU C. M., 1965. L'utilisation des éléments minéraux de la ration par le veau. Ann. Zoolech., 14, 231-245.

* GÜNTHER K., 1967. Zur Frage der Magnesium-Deponierung im Wachsenden Skelett. Disch. fierörztl. Wschr., 74, 439-442.

HABENER J. F., POTTS J. T. Jr., 1976. Relative effectiveness of magnesium and calcium on the secretion and biosynthesis of parathyroid hormone in vitro. Endocrinology, 98, 197-202.

HAHN T. J., CHASE L. R., AVIOLI L. V., 1972. Effect of magnesium depletion on responsiveness to PTH in parathyroidectomized rats. J. clin. Invest., 51, 886-891.

HAMILTON J. W., SPIERTO F. W., MCGREGOR R. R., COHN D. V., 1971. Studies on the biosynthesis in vitro of parathyroid hormone. II. The effect of calcium and magnesium on synthesis of parathyroid hormone isolated from bovine parathyroid tissue and incubation medium. J. biol. Chem., 246, 3224-3233.

HANNA S., HARRISON M., MCINTYRE I., FRASER R., 1960. The syndrome of magnesium deficiency in man. Lancet, 2, 7143, 172-175.

HARRINGTON D. D., 1975. Influence of magnesium deficiency on horse foal tissue concentrations of $\mathrm{Mg}, \mathrm{Ca}$ and P. Br. J. Nutr., 34, 45-57.

HEATON F. W., 1964. The action of the parathyroid glands during magnesium deficiency in the rat. Biochem. J., 92, 50P.

HEATON F. W., 1965a. Effect of magnesium deficiency on plasma alkaline phosphatase activity. Nature, 18, 1292-1293.

HEATON F. W., 1965b. The parathyroid glands and magnesium metabolism in the rat. Clin. Sci., 28, 543-553.

HEATON F. W., 1971. The physiological relation between magnesium and the skeleton, 165-174. In DURLACH J., 1er Symp. int. Déficit magnésique en pathologie humaine, Vittel, 9-15 mai 1971.

HEROUX O., PETER D., TANNER A., 1975. Effect of a chronic suboptimal intake of magnesium on magnesium and calcium content of bone and on bone strength of the rat. Can. J. Physiol. Pharmacol., 53, 304-310.

HJERPE C. A., 1968. Influence of dietary magnesium on metabolism of calcium and magnesium in sheep. Amer. J. vet. Res., 29, 143-151.

HUNT B. J., BELANGER L. F., 1972. Localized multiform subperiosteal hyperplasia and generalized osteosmyelosclerosis in magnesium deficient rats. Calc. Tiss. Res., 9, 17-27.

* ITOKAWA Y., FUJIWARA M., 1973. Changes in tissue magnesium, calcium and phosphorus levels in magnesium-deficient rats in relation to thiamine excess or deficiency. J. Nutr., 103, 438-443.

KEIL L. C., EVANS J. W., PRINZ J. A., 1974. Effect of parathyroidectomy on bone growth and composition in the young rat. Growth, 38, 519-527.

* KOLB E., 1972. Untersuchungen über den Mineralstoffgehalt verschiedener Gewebe vom Rind. Arch. exper. Vet. Med., 27, 613-623.

KRUSE H. D., ORENT E. R., MCCOLLUM E. V., 1932. Studies on magnesium deficiency in animals. I. Symptomatology resulting from magnesium deprivation. J. biol. Chem., 96, 519-539.

KUSNER W., MICHAELI Y., WEINREB M. M., 1973. Role of attrition and occlusal contact in the physiology of the rat incisor. 6. Impeded and unimpeded eruption in hypophysectomized and magnesium deficient rats. J. dent. Res., 52, 65-73.

LAI C. C., SINGER L., ARMSTRONG W. D., 1975. Bone composition and phosphatase activity in magnesium deficiency in rats. J. Bone Joint Surg., 57A, 516-522.

LARVOR P., DURLACH J., 1971. Relation entre magnésium et glandes endocrines, 251-296. In DURLACH J., 1er Symp. int. Déficit magnésique en pathologie humaine, Vittel, 9-15 mai 1971.

LARVOR P., GIRARD A., BROCHART M., 1964. Ełude de la carence expérimentale en magnésium chez le veau II. Interférence entre la carence en magnésium et le métabolisme du calcium. Ann. Biol. anim. Bioch. Biophys., 4, 371-382.

* LARVOR P., GIRARD A., BROCHART M., PARODI A., SEVESTRE J., 1964. Etude de la carence 
expérimentale en magnésium chez le veau. I. Observations cliniques, biochimiques et anatomo-pathologiques. Ann. Biol. anim. Bioch. Biophys., 4, 345-369.

* LARVOR P., RAYSSIGUIER Y., 1971. Influence de la démédullation surrénalienne sur le métabolisme du magnésium au cours de la carence en cet élément chez le rat. C. R. Acad. Sci. Paris, sér. $D, 273,1408-1410$.

LEE M. J., ROTH S. I., 1975. Effect of calcium and magnesium on deoxyribonucleic acid synthesis in rat parathyroid glands in vitro. Lab. Invest., 33, 72-79.

LETTERI J. M., BILTZ R. M., ELLIS K. J., MARTINO A., YASUMURA S., BROOK D., COHN S. H., PELLEGRINO E. D., 1977. Total bone carbonate, phosphate, magnesium and calcium in subtotally nephrectomized rats : an estimate of arrested bone growth and mineral maturation in experimental uremia. (Abstr.). 3rd int. Workshop on phosphate and other minerals, Madrid, July 13-15, 1977.

* LIFSHITZ F., HARRISON H. C., HARRISON H. E., 1967a. Effects of vitamin D on magnesium metabolism in rats. Endocrinology, 81, 849-853.

* LIFSHITZ F., HARRISON H. C., HARRISON H. E., 1967b. Response to vitamin D of magnesiumdeficient rats. Proc. Soc. exp. Biol. Med., 125, 472-476.

LITTLEDIKE E. T., ARNAUD C. D., 1971. The influence of plasma magnesium concentrations on calcitonin secretion in the pig. Proc. Soc. exp. Biol. Med., 136, 1000-1006.

LEVI J., MASSRY S. G., COBURN J. W., LLACH F., KLEEMAN C. R., 1974. Hypocalcemia in magnesium-depleted dogs : evidence for reduced responsiveness to parathyroid hormone and relative failure of parathyroid gland function. Mefabolism, 23, 323-336.

LOPEZ DE NOVALES E., 1974. Metabolismo del magnesio en la intoxicación experimental por la vitamina D. Rev. clin. esp., 135, 315-327.

LOVELESS B. W., HEATON F. W., 1976. Changes in the alkaline phosphatase (EC 3.1.3.1) and inorganic pyrophosphatase (EC 3.6.1.1) activities of rat tissues during magnesium deficiency. The importance of controlling feeding pattern. Br. J. Nutr., 36, 487-495.

MCALEESE D. M., FORBES R. M., 1961. The requirement and tissue distribution of magnesium in the rat as influenced by environmental temperature and dietary calcium. J. Nutr., 73, 94-106.

MCCANN H. G., BULLOCK F. A., 1957. The effect of fluoride ingestion on the composition and solubility of mineralized tissues of the rat. J. dent. Res., 36, 391-398.

MCINTYRE I., DAVIDSSON D., 1958. The production of secondary potassium depletion, sodium retention, nephro-calcinosis and hypercalcemia by magnesium deficiency. Biochem. J., 70, 456-462.

McMANUS J., HEATON F. W., 1969. The effect of magnesium deficiency on calcium homeostasis in the rat. Clin. Sci., 36, 297-306.

McMANUS J., HEATON F. W., 1970. The influence of magnesium on calcium release from bone in vifro. Biochim. biophys. Acta, 215, 360-367.

MCMANUS J., HEATON F. W., LUCAS P. W., 1971. A decreased response to parathyroid hormone in magnesium deficiency. J. Endocr., 49, 253-258.

* MARTINDALE L., HEATON F. W., 1964. Magnesium deficiency in the adult rat. Biochem. J., 92, 119-126.

* MARTINDALE L., HEATON F. W., 1965. The relation between skeletal and extracellular fluid magnesium in vitro. Biochem. J., 97, 440-443.

MASSRY S. G., COBURN J. W., KLEEMAN C. R., 1970. Evidence for suppression of parathyroid gland activity by hypermagnesemia. J. clin. Invesf., 49, 1619-1629.

MAYER G. P., 1974. Effect of calcium and magnesium on parathyroid hormone secretion rate in calves, 122-124. In TALMAGE R. V., OWEN M., PARSONS J. A., Proc. 5th Parathyroid Conf., Excerpto med., int. Congr. Ser. 346.

MEHRING A. L. Jr., 1965. The effect of magnesium in limestone on the growth and tibia ash of chicks. Poult. Sci., 44, 345-348.

MELANI F., FARNARARO M., 1969. Evidence for the identity of alkaline phosphatase and inorganic pyrophosphatase in rat kidney. Biochim. biophys. Acta, 178, 93-99.

* MEYER H., BUSSE F. W., 1975. Untersuchungen über Speicherung und Mobilisierung von Magnesium im Organismus. Zbl. Vef. Med., A22, 864-876.

* MEYER H., PETERS E., SCHOLZ H., 1973. Endogene faekale Mg-Ausscheideing, Mg-Versaulickeit 
und Mg-Gehalt verschiedener Organe bei Schafen mit unterschieldlicher Mg-Aufnahme. Disch. tierörztl. Wschr., 80, 160-164.

* Miller E. R., ULLRey D. E., ZUTAUT C. L., BaltZer B. V., SCHMidT D. A., hOEFFer J. A., LUECKE R. W., 1965a. Magnesium requirement of the baby pig. J. Nutr., 85, 13-20.

* Miller E. R., ULLReY D. E., ZUTAUT C. L., hOEFfER J. A., LUECKE R. W., 1965b. Comparison of casein and soy proteins upon mineral balance and vit. $D_{2}$ requirement of the baby pig. J. Nutr., 85, 347-353.

* MILler E. R., ULLReY D. E., ZUTAUT C. L., HOEfFER J. A., LUECKE R. W., 1965c. Mineral balances studies with the baby pig : effects of dietary vitamin $D_{2}$ level upon calcium, phosphorus and magnesium balance. J. Nutr., 85, 255-259.

MILLER E. R., ULLREY D. E., ZUTAUT C. L., HOEFFER J. A., LUECKE R. W., 1965d. Mineral balance studies with the baby pig : effects of dietary magnesium level upon calcium, phosphorus and magnesium balance. J. Nutr., 86, 209-212.

MORRIS E. R., O'DELL B. L., 1961. Magnesium deficiency of the guinea pig. Mineral composition of tissues and distribution of acid-soluble phosphorus. J. Nutr., 75, 77-85.

NEUMAN W. F., MULRYAN B. J., 1971. Synthetic hydroxyapatite crystals. IV. Magnesium incorporation. Calc. Tiss. Res., 7, 133-138.

NEUMAN W. F., NEUMAN M. W., 1958 . The chemical dynamics of bone mineral. Univ. of Chicago Press, Chicago.

NIELSEN S. P., 1970. Abolition of magnesium-induced hypocalcaemia by acute thyroparathyroidectomy in the cat. Acta endocr., 64, 150-158.

NIELSEN S. P., 1971. Calcitonin and magnesium homeostasis, 203-209. In DURLACH J., 1er Symp. int. Déficit magnésique en pathologie humaine, Vittel, 9-15 mai 1971.

NIELSEN S. P., 1973. Effects of magnesium on calcification of young bone in tissue culture. Calc. Tiss. Res., 11, 78-94.

NIELSEN S. P., 1974. Inferrelations of magnesium and calcium metabolism. Doct. Thesis, Fac. Medicine, Univ. Copenhagen, Munksgaard Copenhagen, 158 pp.

O'DELL B. L., MORONO R. I., REGAN W. O., 1973. Interaction of dietary fluoride and magnesium in guinea pigs. J. Nutr., 103, 841-850.

O'DELL B. L., MORRIS E. R., REGAN W. O., 1960. Magnesium requirement of guinea pigs and rats : effects of calcium and phosphorus and symptoms of magnesium deficiency. J. Nutr., 70, 103-111.

OPHAUG R. H., SINGER L., 1976. Effect of fluoride on the mobilization of skeletal magnesium and soft-tissue calcinosis during acute magnesium deficiency in the rat. J. Nutr., 106, 771-777.

ORENT E. R., KRUSE H. D., MCCOLLUM E. V., 1934. Studies in magnesium deficiency in animals VI. Chemical changes in the bone with associated blood changes resulting from magnesium deprivation. J. biol. Chem., 106, 573-593.

PAK C. Y. C., DILLER E. C., 1969. Ionic interaction with bone mineral. V. Effect of Mg, citrate, F, sulfate on the solubility, dissolution and growth of bone mineral. Calc. Tiss. Res., 4, 69-77.

PARR W. H., 1957. Hypomagnesaemic tetany in calves fed on milk diets. Vet. Rec., 69, 71-76.

PAYNE J. M., CHAMINGS J., 1964. The effect of thyroparathyroidectomy in the goat with particular respect to clinical effects and changes in the concentrations of plasma calcium, inorganic phosphorus and magnesium. J. Endocrinol., 29, 19-28.

PECK W. A., CARPENTER R. J., CHUSTER S., 1974. Cyclic 3'5'-adenosine monophosphate metabolism in bone cell ghosts : effect of adenosine and parathyroid hormone, 204-212, In TALMAGE R. V., OWEN M., PARSONS J. A., Proc. 5th Parathyroid Conf., Excerpta med., Int. Congr. Ser. 346.

PENTO J. T., GLICK S. M., KAGAN A., GORFEIN P. C., 1974. The relative influence of calcium, strontium and magnesium on calcitonin secretion in the pig. Endocrinology, 94, 1176-1180.

PIMSTONE B., EINSENBERG E., STALLONE W., 1966. Decrease in serum alkaline phosphatase activity produced by magnesium depletion in rats. Proc. Soc. exp. Biol. Med., 123, 201-203.

PLETKA P., BERNSTEIN D. S., HAMPERS C. L., MERRILL J. P., SHERWOOD L. M., 1971. Effects of magnesium on parathyroid hormone secretion during chronic haemodialysis. Lancet, 2 (7722), 462-463.

* POINTILlaRt A., 1976. Effet à moyen terme de la teneur en magnésium d'un régime riche en 
huile de Primor sur l'apparition des lésions du myocarde chez le rat. Ann. Biol. anim. Bioch. Biophys., 16, 891-895.

POINTILLART A., GAREL J. M., GUEGUEN L., 1978a. Calcemia regulation in the vitamin D deficient growing pig. Ann. Biol. anim. Bioch. Biophys., 18, 167-174.

POINTILLART A., GAREL J. M., GUEGUEN L., 1978b. Plasma calcitonin and parathyroid hormone levels in growing pigs on different diets. I. High phosphorus diet. Ann. Biol. anim. Bioch. Biophys., 18, 699-709.

POINTILLART A., GUEGUEN L., GAREL J. M., 1977. Calcitonine, parathormone et déséquilibre phosphocalcique alimentaire chez le porc. Journées Rech. porcine en France. Ed. ITP, 283-288.

POTTS J. T. Jr., BUCKLE R. M., SHERWOOD L. M., RAMBERG C. F. Jr., MAYER G. P., KRONFELD D. S., DEFTOS L. J., CARE A. D., AURBACH G. D., 1968. Control of secretion of parathyroid hormone. In : Parathyroid hormone and thyrocalcitonin. Eds. TALMAGE R. V., BELANGER L. F., CLARK I., p. 407, Excerpta Medica Foundation, New York.

PUCHE R. C., LOCATTO M. E., FERETTI J. L., FERNANDEZ M. C., BORSATTI M., VALENTI J. L., 1976. The effects of a long term feeding of Solanum glaucophyllum to growing rats on $\mathrm{Ca}, \mathrm{Mg}, \mathrm{P}$ and bone metabolism. Calc. Tiss. Res., 20, 105-119.

PYKE R. E., HOEKSTRA N. G., PHILLIPS P. H., 1967. Effects of fluoride on magnesium deficiency in the guinea pig. J. Nutr., 92, 311-316.

RADDE I. C., WITTERMANN E. R., PENSUWAN S., 1968. Effect of thyroid and parathyroid on hypocalcemia occuring after a magnesium load. Endocrinology, 83, 1285-1292.

RAISZ L. G., NIEMANN I., 1969. Effect of phosphate, calcium and magnesium on bone resorption and hormonal responses in tissues cultures. Endocrinology, 85, 446-452.

RAMP W. K., THOMAS J. R., NIFONG P. D., 1977. Magnesium and the mineral metabolism of chick embryo tibia in organ culture. Calc. Tiss. Res., 24, 93-98.

RANDOIN L., CAUSERET J., 1945. Recherches expérimentales relatives à l'influence de la teneur du régime alimentaire en phosphore, en calcium, en magnésium et en vitamine $D$, sur le développement osseux du rat blanc. Bull. Soc. Hyg. Alim., 33, 13-22.

RAYSSIGUIER Y., 1977. The influence of the thyroid and parathyroid glands on the variations in magnesemia in fed and fasted rats. Horm. Metab. Res., 9, 161-163.

RAYSSIGUIER Y., AYIGBEDE O., MIRAVET L., 1974. Métabolisme et activité du cholécalciférol et de quelques dérivés hydroxylés chez le rat en carence magnésique. C. R. Acad. Sci. Paris, sér. $D, 278,1613-1616$.

RAYSSIGUIER Y., BADINAND F., KOPP J., Effect of magnesium deficiency on parturition and uterine involution in the rat (à paraitre, 1978).

RAYSSIGUIER Y., CARRE M., AYIGBEDE O., MIRAVET L., 1975. Activité du 1-25 dihydroxycholécalciférol chez le rat carencé en magnésium. $C$. R. Acad. Sci. Paris, sér. D, 281, 731-734.

RAYSSIGUIER Y., GAREL J. M., DAVICCO M. J., BARLET J. P., 1977. Parathyroid hormone and calcitonin in magnesium-deficient calves. Horm. Melab. Res., 9, 438-439.

RAYSSIGUIER Y., LARVOR P., 1964. Parathyroid response to hypocalcemia in magnesium deficient rat. Horm. Metab. Res., 6, 91.

RAYSSIGUIER Y., LARVOR P., 1974. Variations nycthémérales de la magnésémie chez le rat : influence du jeûne et de la réplétion stomacale. Ann. Biol. anim. Bioch. Biophys., 14, 821-827.

* RAYSSIGUIER Y., LARVOR P., 1974. Influence du calcium alimentaire sur les calcifications rénales, la magnésémie et le magnésium osseux du rat carencé en magnésium. Ann. Biol. anim. Bioch. Biophys., 14, 145-146.

RAYSSIGUIER Y., LARVOR P., 1978. Mineral bone composition and some elements of calcium metabolism in magnesium-deficient growing rats. Ann. Biol. anim. Bioch. Biophys., 18, 157-166.

RAYSSIGUIER Y., LARVOR P., BARLET J. P., 1973. Ełude de l'influence d'un phosphonate de sodium sur le taux rénal de calcium chez le Rat carencé en magnésium. C. R. Acad. Sci. Paris, sér. D. 276, 2035-2038.

REDDY V., SIVAKUMAR B., 1974. Magnesium-dependent vitamin D-resistant rickets. Lancet, 1, (7864), 963-965.

REVUSOVA V., GRATZloVA J., ZVARA V., PRIBYLINCOVA V., BOROSOVA E., REZNICEK J., 1977. Hypomagnesemia in chronic renal insufficiency as a consequence of vitamine $D$ deficiency. (Abstr.). 3rd int. Workshop on phosphate and other minerals. Madrid, July 13-15, 1977. 
RICHARDSON J. A., WELT L. G., 1965. The hypomagnesemia of vitamin D administration. Proc. Soc. exp. Biol. Med., 118, 512-514.

RUDE R. K., OLDMAN S. B., SHARP C. F., SINGER F. R.,1977. Effects of magnesium on parathyroid secretion in man. (Abstr.) 3rd int. Workshop on phosphate and other minerals, Madrid, July 13-15, 1977.

* SALET J., FOURNET J. P., 1971. Le métabolisme du magnésium et ses méthodes d'exploration en pédiatrie. Ann. Pédiat., 18, 46-52.

SANSOM B. F., ALLEN W. M., DAVIES D. C., HOARE M. N., STENTON J. R., VAGG M. J., 1976. Use of $1 \alpha$-hydroxycholecalciferol in preventing post parturient hypocalcemia and its potential value for the prevention of milk fever in dairy cows. Vet. Rec., 99, 310-312.

SHERWOOD L. M., HERRMAN 1., BASSETT C. A., 1970. Parathyroid hormone secretion in vitro : regulation by calcium and magnesium ions. Nature, 225, 1056-1058.

SLATOPOLSKY E., MERCADO A., MORRISON A., YATES J., KLAHR S., 1976. Inhibitory effects of hypermagnesemia on the renal action of parathyroid hormone. J. elin. Invest., 58, 1273-1279.

SLATOPOLSKY E., ROSENBAUM R., LEWIS J., MENNES P., 1977. The hypocalcemia of magnesium depletion (Abstr.) 3rd int. Workshop on phosphate and other minerals. Madrid, July 13-15, 1977.

* SMITH B. S. W., NISBET D. I., 1968. Biochemical and pathological studies on magnesium deficiency in the rat. I. Young animals. J. comp. Path., 78, 149-159.

* SMITH B. S. W., NISBET D. l., 1972. Biochemical and pathological studies on magnesium deficiency in the rat. II. Adult animals. J. comp. Path., 82, 37-46.

SMITH R. H., 1957. Calcium and magnesium metabolism in calves. Plasma levels and retention in milk fed calves. Biochem. J., 67, 472-481.

* SMITH R. H., 1959. Calcium and magnesium metabolism in calves. 4. Bone composition in magnesium deficiency and the control of plasma magnesium. Biochem. J., 71, 609-614.

SMITH R. H., 1961. Importance of magnesium in the control of plasma calcium in the calf. Nature, 191, 181-182.

SORENSEN O. H., FRIIS Th., HINDBERG I., NIELSEN S. Pors., 1970. The effect of calcitonin injected to hypercalcaemic and normocalcaemic patients. Acta med. scand., 187, $283-290$.

* SORENSEN O. H., HINDBERG I., BANK-MIKKELSEN O., 1971. Hydroxyproline, calcium and magnesium contents of bones in rats after long-ferm freatment with calcitonin. Acta endocr., 68, 203-208.

SPIERTO F., ROGLER J. C., PARKER H. E., 1969a. Effect of dietary magnesium and fluoride on bone mineralization in young chicks. J. Nutr., 98, 271-278.

SPIERTO F., ROGLER J. C., PARKER H. E., 1969b. The effect of magnesium and fluoride on bone pyrophosphatase activity. Proc. Soc. exp. Biol. Med., 132, 568-570.

STEWART W. K., FLEMING L., 1971. Effects of magnesium on parathyroid hormone secretion during chronic haemodialysis. Lancet, 2, (7729) ; 879.

SUH S. M., TASHJIAN A. H., MATSUO N., PARKINSON D. K., FRASER D., 1973. Pathogenesis of hypocalcemia in primary hypomagnesemia : normal end-organ responsiveness to parathyroid hormone, impaired parathyroid gland function. J. clin. Invest., 52, 153-160.

SUSSMAN H. H., LAGA E., 1968. Inorganic pyrophosphatase activity of human placental alkaline phosphatase. Biochim. biophys. Acto, 151, 281-283.

TARGOVNIK J. H., RODMAN J. S., SHERWOOD L. M., 1971. Regulation of parathyroid hormone secretion in vitro : quantitative aspects of calcium and magnesium ion control. Endocrinology, 88, 1477-1482.

TAYLOR T. G., 1959. The magnesium of bone mineral. J. agric. Res., 52, 207-216.

TUFTS E. V., GREENBERG D. M., 1938. The biochemistry of magnesium deficiency. I. Chemical changes resulting from magnesium deficiency. J. biol. Chem., 122, 693-714.

* VAN KEMPEN G. J. M., KERK P. V. D., GRIMBERGEN A. H. M., 1976. The influence of the phosphorus and calcium content of feeds on growth, feed conversion and slaughter quality, and on the chemical, mechanical and histological parameters of the bone tissue of pigs. Neth. J. agric. Sci., 24, 120-139.

WALLACH S., BELLAVIA J. V., SCHORR J., GAMPONIA P. J., 1966. Effecf of vitamine D on tissue distribution and transport of electrolytes ${ }^{47} \mathrm{Ca}$ and ${ }^{28} \mathrm{Mg}$. Endocrinology, 79, 773-782.

WALLING F. W., FAVUS M. J., KIMBERG D. V., 1975. Effect of magnesium deficiency and thyro- 
parathyroidectomy on calcium active transport by rat duodenum. Proc. Soc. exp. Biol. Med., 148, 1038-1043.

WALLING M. W., KIMBERG D. V., 1975. Effects of $1 \alpha, 25$-dihydroxyvitamin $D_{3}$ and Solanum Glaucophyllum on infestinal calcium and phosphate transport and on plasma $\mathrm{Ca}, \mathrm{Mg}$, and P levels in the rat. Endocrinology, 97, 1567-1576.

WALSER M., 1967. Magnesium metabolism. Ergebn. Physiol., 59, 185-341.

WEINREB M. M., KUSNER W., MICHAELI Y., 1973. Role of attrition and occlusal contact in the physiology of the rat incisor. 7. Formation of impeded and unimpeded incisors in magnesiumdeficient rats. J. dent. Res., 52, 498-503.

WIDDOWSON E. M., MCCANCE R. A., SPRAY C. M., 1951. The chemical composition of the human body. Clin. Sci., 10, 113-125.

WÖLTGENS J. H. M., BOUTING S. L., BIJVOET O. L. M., 1970. Relationship between alkaline phosphatase and inorganic pyrophosphatase in young hamster molars. Calc. Tiss. Res., 4 (suppl.), 39.

ZIPKIN I., MCCLURE F. J., LEE W. A., 1960. Relation of the fluoride content of human bone to its chemical composition. Arch, oral. Biol., 2, 190-195. 